\section{Explaining alternative termination modes of international joint ventures}

\author{
Palitha Konara \\ University of Sussex, Falmer, UK \\ Zita Stone \\ University of Kent, Canterbury, UK, and \\ Alex Mohr \\ Department of Global Trade, Vienna University of Economics and Business, \\ Vienna, Austria
}

Alternative termination modes of IJVs

Received 21 February 2019 Revised 18 October 2019 22 January 2020 9 April 2020 19 April 2020 Accepted 19 April 2020

\begin{abstract}
Purpose - The authors combine options logic with transaction cost economics to explain why firms maintain, divest or buy out their international joint ventures (IJVs). It is suggested that a decline in environmental risk and higher partner-related risk makes a firm more likely to acquire an IJV but less likely to divest an IJV. The study also investigates how IJV age moderates the effects of a decline in environmental risk and higher partnerrelated risk.

Design/methodology/approach - The study employs competing risks analyses to examine the drivers of different termination outcomes using a dataset consisting of 459 IJVs in the People's Republic of China, of which 110 were either acquired or divested by their foreign parent.

Findings - The study finds that changes in environmental risk and partner-related risk affect how firms terminate their IJVs in the People's Republic of China. Specifically, the authors find that the effect of exogenous and endogenous risk are more pronounced for the acquisition of IJVs than for the divestment of IJVs.

Research limitations/implications - The study contributes to international marketing research by complementing options logic with transaction cost economics to provide a theoretical explanation of the different ways in which IJVs in the People's Republic of China are terminated.

Practical implications - IJVs continue to be an important yet often unstable method to serve international markets. Our findings increase managers' awareness of the effect that two important sources of risk may have on the termination of IJVs in the People's Republic of China.

Originality/value - The study provides novel insights into the effect that changes in exogenous and endogenous risk have on a firm's choice of termination mode drawing on novel data on the different ways in which foreign firms have terminated their IJVs in the Peoples' Republic of China.
\end{abstract}

Keywords Joint ventures, Transaction costs, Environmental risk, IJV age, Options logic

Paper type Research paper

\section{Introduction}

The establishment of an international joint venture (IJV) as an entry mode when firms seek to expand overseas is a topic that has been widely considered in international marketing research, drawing on theories, such as transaction cost economics (TCE) and the real options perspective (e.g. Brouthers et al., 2003; 2008; Kogut, 1988a; Nippa and Reuer, 2019; Surdu et al., 2018). In contrast, we still know relatively little about why and how firms terminate an IJV. Firms can terminate an IJV in different ways, for example, by selling their stake in an IJV or

(C) Palitha Konara, Zita Stone and Alex Mohr. Published by Emerald Publishing Limited. This article is published under the Creative Commons Attribution (CC BY 4.0) licence. Anyone may reproduce, distribute, translate and create derivative works of this article (for both commercial \& non-commercial purposes), subject to full attribution to the original publication and authors. The full terms of this licence may be seen at http://creativecommons.org/licences/by/4.0/legalcode

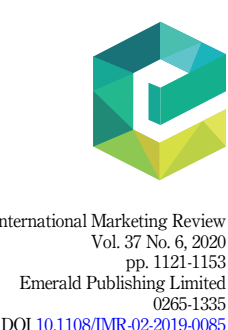

DOI 10.1108/IMR-02-2019-0085 
IMR

37,6

\section{2}

by acquiring their partner's stake. Importantly, different ways of terminating an IJV, i.e. different IJV termination modes, are likely to be driven by different factors, and the same factor may have different effects on alternative IJV termination modes (e.g Mata and Portugal, 2015). Factors that increase a firm's propensity to buy out its partner may have the opposite effect on its propensity to divest an IJV. Just as one cannot assume that the determinants of foreign entry are the same across different entry modes, we cannot presume that the causes of foreign divestment are the same across different exit modes (Engel et al., 2013; Meschi and Wassmer, 2013; Nemeth and Nippa, 2013). The current lack of understanding of what drives different IJV termination modes prevents international marketing researchers from comparing the findings of prior research on the determinants of IJV dissolution (Kogut, 1989; Meschi, 2005; Meschi and Riccio, 2008) and thus from providing clear guidance to marketing practitioners. There is thus a need to explain the different termination outcomes of IJVs. Drawing on various theories, particularly on TCE and the real options perspective, existing international marketing research has put particular emphasis on the role that exogenous and endogenous risk [1] plays in the management of IJVs and in explaining IJV termination in general (Harrigan, 1985; Hennart and Zeng, 2002; Kogut, 1989). Based on this suggested importance of exogenous and endogenous risk, we extend this research by examining how these risks affect a firm's choice of IJV termination mode.

Exogenous risk relates to the possible changes in a firm's environment that affect a firm's operations, that is, risks arising from changes in the overall economic, political or financial environment of a host country or from changes in the environment of the specific industry the IJV operates in (e.g Chi and McGuire, 1996; Kogut, 1991; Krishnan et al., 2006). Such exogenous risks are particularly pronounced in emerging economies, where environmental changes are more likely and more pronounced when compared to those in developed economies (Puck et al., 2013). Exogenous risk is beyond the firm's control. Prior research shows that such changes in the environment can affect the viability of an IJV and thus threaten its survival (Kogut, 1989; Meschi, 2005; Meschi and Riccio, 2008). While prior research has looked at the effect of exogenous risk on IJV dissolution in general, we do not know if changes in the exogenous affect have different effects on different types of IJV termination. Our first research question is thus: How does a decline in the level of environmental (i.e. political, economic and financial) risk affect firms' choice of IJV termination mode?

In contrast to exogenous risk, endogenous risks are within a firm's control; i.e. these are risks that can be influenced by firms themselves (Ahsan and Musteen, 2011; Everett and Watson, 1998). Prior research has discussed various factors that affect IJV dissolution by increasing endogenous risk (e.g. Dhanaraj and Beamish, 2004; Park and Russo, 1996). In the context of an IJV, one of the key endogenous risks relates to the firm's partner because the partner's motives, capabilities, and operating style cannot be known ex ante and there is a risk that the partner behaves opportunistically (Chi and McGuire, 1996; Gulati and Singh, 1998; Krishnan, et al., 2006). This partner-related risk increases with the number of partners involved in an IJV (e.g. Chung and Beamish, 2012) and is a particular concern in countries where IJVs with multiple partners are more common due to greater government interference in business, such as, for example, the Peoples' Republic of China (PRC) (Mohr et al., 2016a, b). To date, however, little attention has been paid to how endogenous risk, specifically the risk associated with an increase in the number of IJV partners, affects a firm's choice of a specific IJV termination mode. Our second research question is thus: How does the partner-related risk arising from multiple partners affect a firm's choice of IJV termination mode?

Prior research has highlighted the effects of exogenous and endogenous risk on IJV dissolution, but the mixed evidence so far suggests that these effects may be contingent on particular characteristics of the partners and/or the IJVs (Nemeth and Nippa, 2013). Although research has looked at the direct effect of IJV age on IJV survival (e.g. Dhanaraj and Beamish, 
2004; Hennart and Zeng, 2002), an IJV's age may moderate the effects of exogenous and endogenous risk on IJV survival in general and on a firm's choice of IJV termination mode. The literature on the evolution of firms suggests that a firm's susceptibility to exogenous risk varies over time. Older firms may have developed resources and routines to deal with environmental change and may also be less likely to reverse an investment decision because of escalating commitment (Freeman et al., 1983; Sørensen and Stuart, 2000; Thornhill and Amit, 2003). However, so far, we do not know if the effects of exogenous risk on a firm's choice of IJV termination mode vary over the lifetime of an IJV. We thus address the following third research question: How does IJV age moderate the effect of a decline in environmental risk on a firm's choice of IJV termination mode?

An IJV's age may also moderate the effect of endogenous risk on IJV survival. Prior research suggests that over time, firms involved in IJVs develop relational capital (Park and Russo, 1996; Slater and Robson, 2012). Because such relational capital is associated with a decline in the (perceived) threat of opportunistic behavior (Park and Russo, 1996; Slater and Robson, 2012), it may mitigate the effect that endogenous, partner-related risk has on IJV termination. To date, however, our understanding of such a potential moderating effect of age is limited. Our fourth research question is thus: How does IJV age moderate the effect of partner-related risk on a firm's choice of IJV termination mode?

We address these four research questions by combining the options perspective with insights from TCE to examine how firms terminate their IJVs in the PRC and thus make the following contributions. First, we contribute to a better understanding of firms' choices of IJV termination modes by providing an explanation of both divestment and acquisition that accounts for the roles of exogenous and endogenous risk. Second, we contribute to the development of options logic in the context of IJVs by complementing its focus on exogenous risk with arguments from TCE to examine the effects of endogenous risk and the moderating role of IJV age. In so doing, we contribute to the development of options logic by showing that the relationships implied by options logic are affected by constructs that are taken from TCE.

We address our four research questions in the context of IJVs in the People's Republic of China (PRC), where IJVs continue to constitute a central means for foreign firms to enter the market. Moreover, the active role of the Chinese government in shaping the environment of foreign businesses and the associated changes in environmental risk make the PRC a good setting to analyze the effects of changes in environmental risk on a firm's choice of IJV termination mode. We use data on 459 IJVs in the PRC that were established from 1985 to 2010 and either continued to operate as of the end of 2014 or were bought out or divested by the foreign partner during this period.

\section{Literature review}

The determinants of firms' choices regarding joint ventures when entering foreign markets have received considerable attention in international marketing research (e.g. Brouthers, et al., 2003; 2008; Surdu et al., 2018). Given the growing importance of the PRC and the continued importance of collaborative entry modes when investing in the PRC, research has put particular emphasis on explaining how firms enter the Chinese market (e.g Fong et al., 2014; He et al., 2019). In contrast to explaining firms' choices regarding IJVs in terms of the alternative modes of entry, there has been comparatively little research into why firms abandon joint ventures (e.g Dhanaraj and Beamish, 2004; Inkpen and Beamish, 1997). Additionally, these studies did not account for the fact that IJVs may be terminated in different ways. The following Table 1 shows selected empirical studies that examined IJV termination in general, i.e. without differentiating between distinct IJV termination modes.

Most of the determinants of IJV dissolution that are investigated by the abovementioned studies are related to either exogenous risk, i.e. risk that cannot be controlled by the firm, or 
IMR
37,6

\section{4}

葛

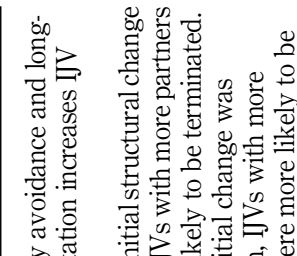

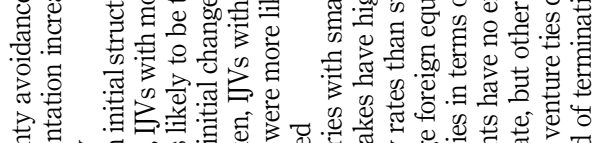

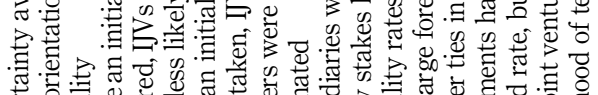

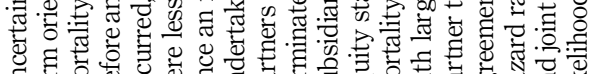

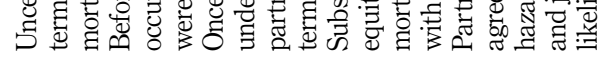

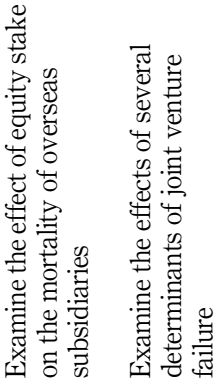

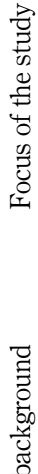

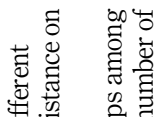

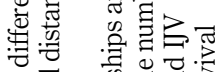
莒

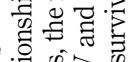

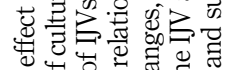
\&

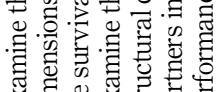

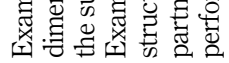
造营

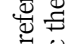

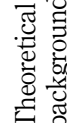
:

这 क

인

됙

号

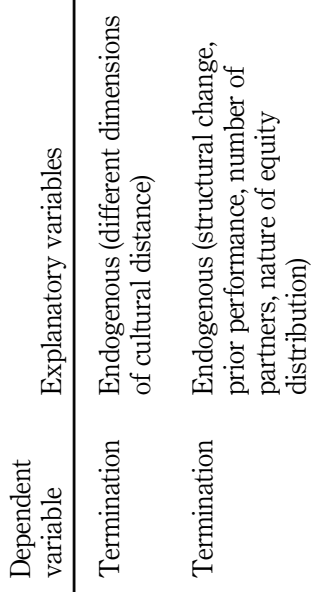

Table 1.

Selected empirical studies on IJV termination (without differentiation of termination outcomes)

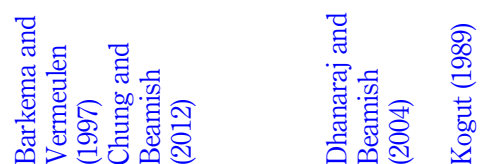

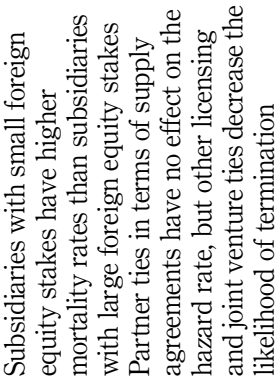

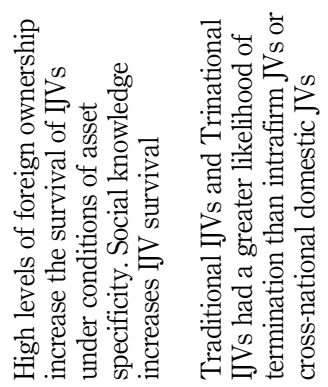

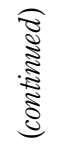

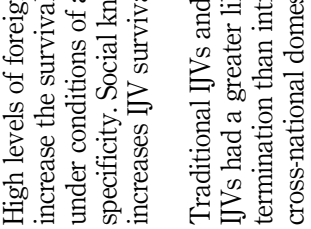
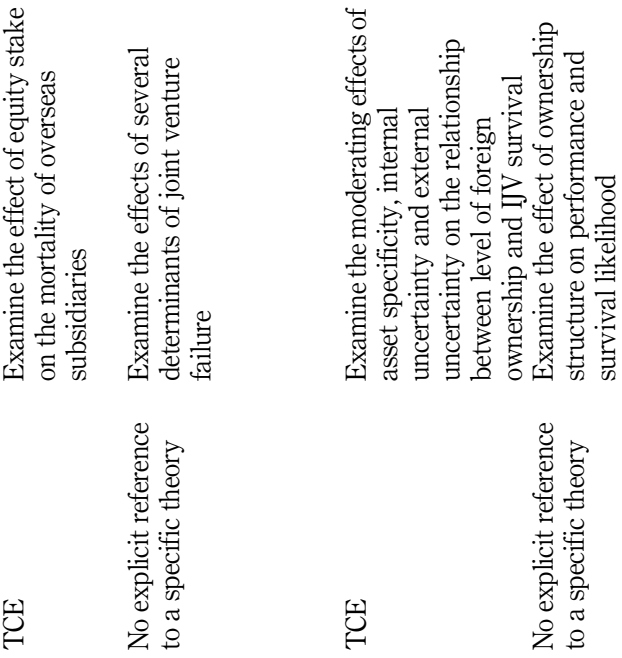

뉩
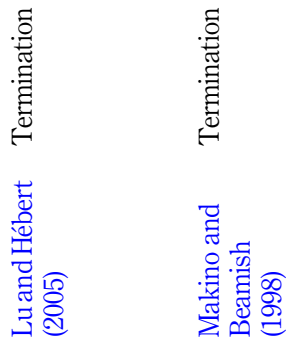


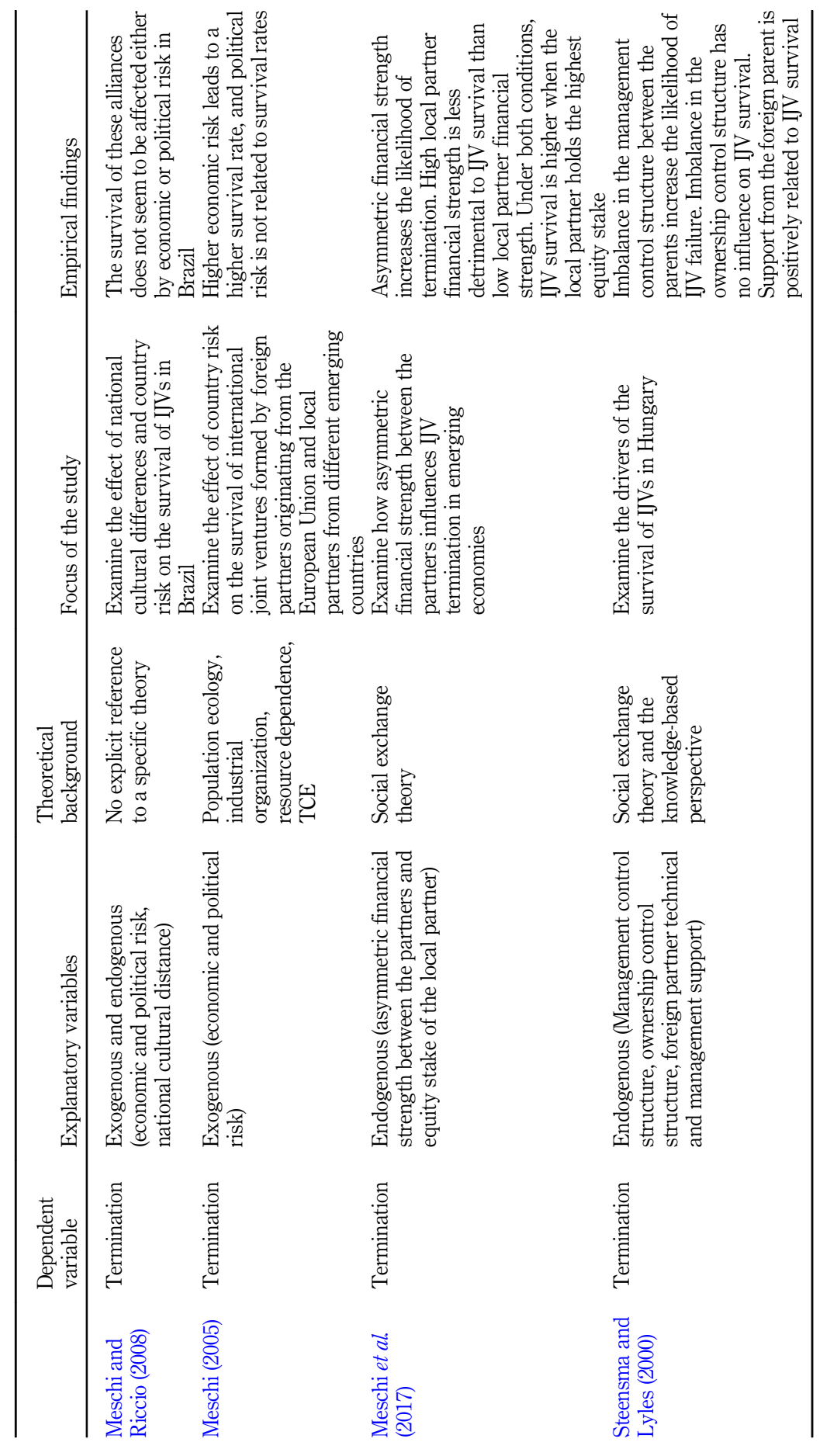

Alternative termination modes of IJVs

1125

Table 1. 
IMR 37,6

1126

endogenous risk, i.e. risk that is shaped by firm decisions. Prior research has investigated how various factors related to exogenous risk affect IJV survival (Kogut, 1989; Meschi, 2005; Meschi and Riccio, 2008). Meschi (2005), for example, analyzed the effect of different facets of environmental risk on the survival of IJVs and found that higher economic risk promotes IJV survival, whereas IJV survival is not significantly affected by political risk. In contrast, Meschi and Riccio (2008) expected economic and political risk to affect IJV survival but found no empirical support for this hypothesis. Studies on the impact of exogenous risk on IJV survival in general have often produced mixed results regarding the effect of exogenous risk on the survival of IJVs, which highlights the potential importance of moderators.

Prior research has also examined the effect of factors related to endogenous risk. Studies have investigated, for example, the equity stake in IJVs (Dhanaraj and Beamish, 2004), the equity structure of IJVs (Lu and Hébert, 2005; Makino and Beamish, 1998; Steensma and Lyles, 2000), the international and host country-specific experience of the foreign firm (Lu and Hébert, 2005), whether partners have collaborated before or continue to collaborate in other IJVs (Kogut, 1989), and the cultural distance between IJV partners (Barkema and Vermeulen, 1997; Tower et al., 2019). Studies of the factors related to endogenous risk have specifically highlighted partner-related risk and the increase in such risk associated with a growing number of partner firms because multiparty IJVs are inherently more complex due to the relationships among multiple partners; many of these studies focused on IJVs in the PRC (see, for example, Beamish and Kachra, 2004; Chung and Beamish, 2012; Mohr et al., $2016 \mathrm{a}, \mathrm{b})$. As in the case of studies of the effects of exogenous risk on IJV survival, research into the effects of the factors related to endogenous risk on IJV survival has also provided mixed findings. With regard to multiparty IJVs, for instance, while some studies find IJV survival rates decrease with the number of partners, other studies find the opposite or suggest a contingent effect (Chung and Beamish, 2012; Mohr et al., 2016a, b), which suggests that the effects of endogenous risks on IJVs might be contingent on characteristics of the IJV and/or its partners.

Overall, while international marketing researchers have studied the dissolution of joint ventures, there has been very little research on how firms terminate joint ventures, i.e. through selling the joint venture or acquiring the partner firm's stake. Existing studies of IJV termination regularly refer to different termination modes, including the sale of a partner's stake to the other partner(s), the sale of a partner's stake to a third party, the sale of all partners' stakes to other parties, and the liquidation of the IJV (see, for instance, Hennart and Zeng, 2002). Although studies have explained IJV dissolution in general, there has been comparatively little research investigating the drivers of such different termination outcomes (please see Table 2).

As in the case of studies examining IJV dissolution in general, this research has focused on determinants that are either exogenous or endogenous. Examining exogenous risk, Kogut (1991), for example, investigated how unexpected increases in the value of the venture and the degree of concentration in a JV's industry affect the likelihood that a JV is acquired by one of the partners. In a post-hoc test, Kogut (1991) found that the rates of termination through acquisition are more stable than the rates of termination through dissolution. A comparatively larger number of studies have examined the role of endogenous factors in IJV termination outcomes (see, for example, Dussauge et al., 2000; Mata and Portugal, 2015; Park and Russo, 1996). Park and Russo (1996) examined the effect of several determinants of joint venture failure, including the effect of the number of partners in the joint venture. Although differentiating between acquisitions and failures was not their main focus, Park and Russo (1996) found that joint venture failures are linked to a different set of causal variables than their acquisitions by one of the partners. In a similar vein, Dussauge et al. (2000) compared the duration of link and scale alliances and suggested that technically oriented link alliances are more likely to be acquired than scale alliances. 


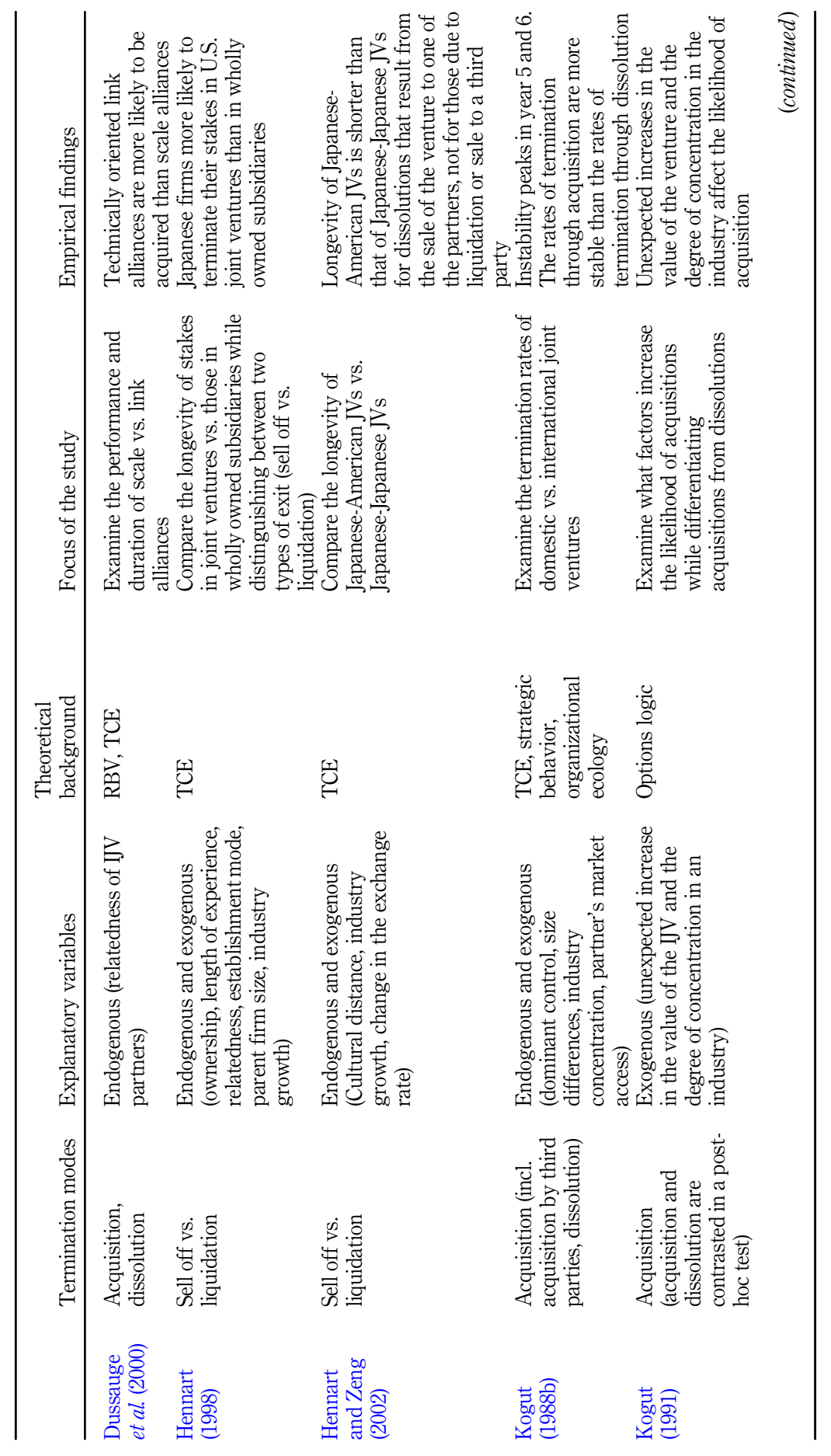

Alternative termination modes of IJVs

1127
Table 2

Selected empirical studies on IJV dissolution with differentiation of termination outcomes 
IMR

37,6

1128

Table 2.

莒

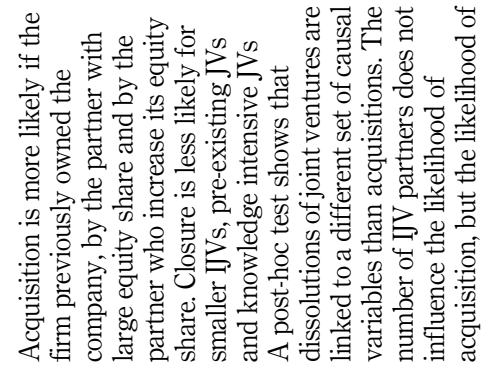

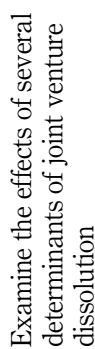

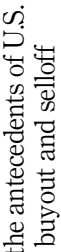

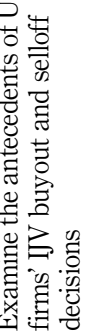

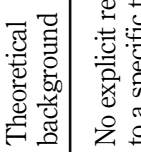

뇐

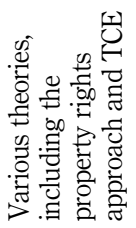

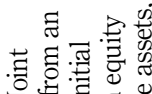

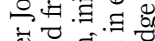

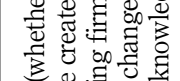

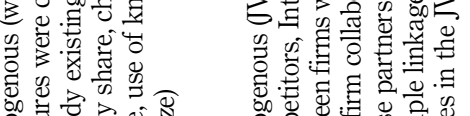

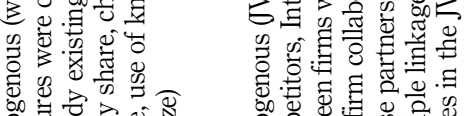

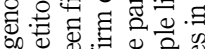

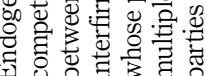

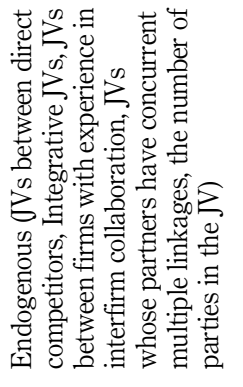

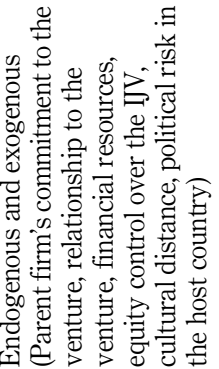

幽弯芯

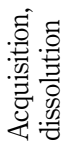

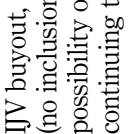

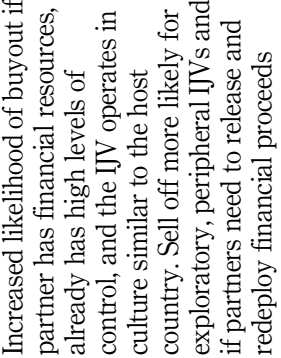

E

8

总

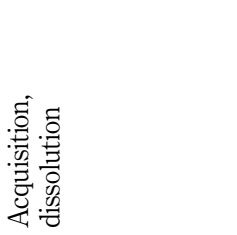

量㩆

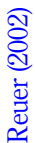


Various studies have highlighted the need to include factors related to exogenous risk as well as factors related to endogenous risk when explaining IJV termination outcomes (Hennart et al., 1998; Hennart and Zeng, 2002; Kogut, 1988b; Reuer, 2002). For example, Kogut (1988b) examined the effects of dominant control, size differences, industry concentration, and a partner's market access on the termination rates of domestic vs. international joint ventures, which he differentiated into acquisitions (including those of third parties) and dissolutions. Similarly, Hennart et al. (1998) discussed the effects of ownership, length of experience, relatedness, the establishment mode, parent firm size and industry growth on the longevity of the stakes in joint ventures vs. those in wholly owned subsidiaries while distinguishing between two types of exit (sell off vs. liquidation). Hennart et al. (1998) also found that Japanese firms were more likely to terminate their stakes in US joint ventures than in wholly owned subsidiaries. In addition, prior research has provided explanations of IJV performance that draw on factors related to both exogenous and endogenous risk (Krishnan et al., 2006).

In both areas of research, i.e. explaining IJV termination in general and explaining IJV termination modes in particular, scholars have adopted a number of different theoretical frameworks to examine the drivers of IJV termination (see Tables 1 and 2). Apart from TCE, which has also been the central approach used to explain choices regarding IJVs in terms of the alternative modes of operation, options logic has been one of the central theoretical explanations used to explain the termination of IJVs (Chi and McGuire, 1996; Reuer and Tong, 2007; Tong et al., 2008). Various researchers have combined different theoretical approaches when explaining a firm's choice of IJV termination modes (Kogut, 1988b; Reuer, 2002).

Overall, while there has been some progress on differentiating IJV termination modes, we still know very little about what drives these different termination modes. Differentiating and understanding what drives firms' choices of IJV termination modes is crucial, as it could be one reason for the inconsistent empirical evidence. In this context, it is noteworthy that in general, existing studies on IJV termination have focused on either exogenous factors or endogenous factors, while relatively few studies have attempted to provide explanations that account for both types of risk. We suggest that explaining firms' choices of IJV termination modes must account for both exogenous and endogenous risk.

\section{Theoretical background}

Existing research that combined different theoretical approaches has made particularly strong contributions to both our understanding of a firm's choice of a JV (e.g Brouthers et al., 2008; Chi and McGuire, 1996; Folta and Leiblein, 1994) and to our knowledge of why firms terminate IJVs (Meschi, 2005; Steensma and Lyles, 2000). The usefulness of combining theoretical approaches has also been highlighted when explaining firms' choices of IJV termination modes (Kogut, 1988b; Nippa and Reuer, 2019; Reuer, 2002). Prior research has often combined TCE and the options perspective because of their respective usefulness in explaining IJVs as well as their complementary assumptions (Brouthers et al., 2008). We suggest that the comparatively greater focus of the options perspective on changes in exogenous risk should be complemented with attention to endogenous risk, which is central to TCE. By combining options logic and TCE, our model is thus able to account for the effects of both exogenous and endogenous risk on a firm's choice of termination mode. Specifically, we draw on options logic to examine how changes in exogenous risk affect how firms terminate their IJVs in the PRC. We then draw on TCE to discuss the effects of endogenous risk on a firm's choice of IJV termination and how the effects of both exogenous and endogenous risk might be contingent on how long an IJV has operated in the PRC.

Options logic has been used in international marketing research to examine, for example, international franchising (Madanoglu et al., 2017) and strategic flexibility in export expansion
Alternative termination modes of IJVs

1129 
IMR

37,6

\section{0}

(Pauwels and Matthyssens, 2004). Prior research that draws on options logic in the context of joint ventures has focused on the conditions under which a firm is likely to view an IJV as a strategic option (e.g. Chi and McGuire, 1996; Cuypers and Martin, 2010; Reuer and Tong, 2005), the choice of an IJV as an entry mode (Brouthers et al., 2008; Folta, 1998), and the option value that is associated with operating and terminating an IJV (Chi and McGuire, 1996; Kumar, 2005; Reuer and Tong, 2007; Tong, et al., 2008). Options logic views IJVs as providing firms with the option to divest, to maintain or to acquire an investment depending on the development of the environmental conditions in the host country (Kogut, 1991; Reuer and Tong, 2007). Alternative IJV termination outcomes thus reflect firms' exercise of one of the two options embedded in IJVs, whereas the decision not to exercise either option leads to the maintenance of the IJV. Although the decisions regarding whether and when to exercise the options are core elements of options logic (Folta, 1998), there has been little research on the conditions that affect firms' decisions to exercise the call (acquisition) or put (divestment) options embedded in IJVs.

Options logic shares its focus on the role of risk with TCE logic, which has provided a central explanation of a firm's choice of an IJV to enter overseas markets (e.g. Hennart, 1988). TCE has also been used to explain IJV termination in general, putting particular emphasis on the endogenous, partner-related risk faced by firms establishing JVs (Chung and Beamish, 2012; Dhanaraj and Beamish, 2004; Lu and Hébert, 2005). Central to TCE are the concepts of bounded rationality and opportunistic behavior, which create uncertainty for firms, specifically with regard to the protection of tangible and intangible assets (Hennart, 1988). This uncertainty in turn affects firms' decisions regarding how to organize economic transactions and thus whether to adopt an IJV as a mode to enter a foreign market (Brouthers et al., 2003).

Both options logic and TCE put particular emphasis on the risks associated with IJVs but put slightly different emphasis on exogenous vs. endogenous risks. Similar to studies that have combined both theories to explain the entry mode (e.g Brouthers et al., 2008; Chi and McGuire, 1996; Folta and Leiblein, 1994), we suggest that such a combination is useful to explain a firm's choices of IJV termination modes. Based on this combination of options logic and TCE we develop hypotheses that link changes in exogenous and endogenous risk to a firm's choice of IJV termination mode. Our conceptual framework in Figure 1 shows the hypotheses that we develop in the next section. We expect that a decline in environmental risk and the number of IJV partners - as a proxy for endogenous risk - affect the two IJV termination modes, i.e., buy-out and divestment. Additionally, because of various mechanisms associated with TCE, particularly the decline in perceived opportunism in IJVs over time, we argue the age of an IJV to affect the direct effects of exogenous and endogenous risk on IJV termination modes.

Figure 1.

Conceptual framework

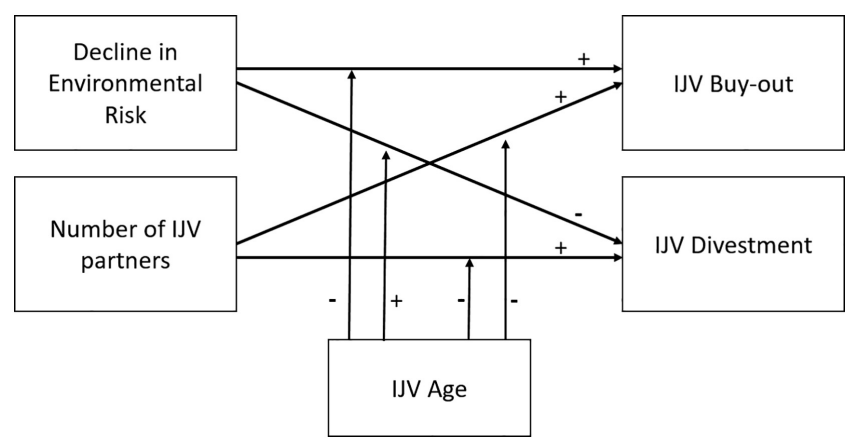




\section{Hypothesis development}

\subsection{Environmental risk and firms' choice of IJV termination mode}

According to options logic, firms establish IJVs to obtain the option to divest, maintain, or acquire an IJV depending on the development of the risk related to the investment. A change in this risk affects the value of the investment in an IJV and of the different options embedded in this investment. The level of exogenous risk is central to a firm's decision to invest in an option (Ahsan and Musteen, 2011), and the values of both the option to acquire and the option to divest that are embedded in an IJV depend on the level of risk (Chi and McGuire, 1996). Because a decline in environmental risk increases the value of the call option (acquisition) but reduces the value of the put option (divestment), options logic would imply that a decline in environmental risk would have opposite effects on firms' decisions to divest and acquire IJVs.

When environmental risk declines, the call option, i.e. the option to acquire the IJV from the local partner(s), becomes more valuable, and the exercise of this option through the acquisition of the IJV thus becomes more likely. Under such conditions, the acquisition of an IJV allows foreign firms to "capitalize on the growth option" that is embedded in the IJV (Tong et al., 2008: 1014) and "respond to favorable environmental conditions in a timely manner before they are dissipated by competitors" (Kumar, 2005: 323). Similarly, Kogut (1991) argues that firms are more likely to acquire an IJV, that is, to exercise the call option, if there is an unexpected but favorable demand shock, for example, a decline in environmental risk in the economic domain. Accordingly, we formulate the following hypothesis:

H1a. A decline in environmental risk increases the likelihood that a foreign partner will acquire an IJV.

In contrast, a decline in environmental risk reduces the value of the put option, which makes firms less likely to exercise this option through the divestment of an IJV (Ahsan and Musteen, 2011; Kogut, 1991). Options logic suggests that IJVs - in contrast to wholly owned subsidiaries - provide multinational enterprises with the option to quickly and easily divest operations and to relocate operations to less risky locations (Chung et al., 2013). As environmental risk declines, the value of the greater flexibility that is associated with IJVs decreases (Tan and Sousa, 2015). This, in turn, reduces the value of the put option and thus diminishes the likelihood that a firm will exercise its put option by divesting the IJV. Therefore, based on options logic, a decline in environmental risk should decrease the likelihood of IJV divestment. Based on this discussion, we formulate the following hypothesis:

H1b. A decline in environmental risk reduces the likelihood that a foreign partner will divest an IJV.

In both cases, the alternative to exercising the option is to maintain the IJV. Without a decline in environmental risk, the option to defer remains more valuable than either the put or the call option (Ahsan and Musteen, 2011; Kumar, 2005; Papyrina, 2007; Tan and Sousa Carlos, 2015). In this situation, a firm will maintain the IJV and continue to monitor the development of environmental risk.

\subsection{Partner-related risk and firms' choice of IJV termination mode}

TCE suggests that partner-related risk constitutes a central element of endogenous risk in IJVs. Partner-related risk relates to the risk that the partner firm will behave opportunistically (Ali and Larimo, 2016; Chi and McGuire, 1996; Lu and Hébert, 2005). The level of partnerrelated risk increases with the number of partners involved in an IJV. This is because of the higher monitoring and coordination costs, greater levels of imperfect information, the higher degree of managerial complexity, the likely larger number of ex post disagreements, and the
Alternative termination modes of IJVs 
IMR

37,6

1132

greater chance of dysfunctional pairings (Beamish and Kachra, 2004; Chung and Beamish, 2012; Park and Russo, 1996; Parkhe, 1993). Because allocating responsibility becomes more difficult with an increase in the number of partners, opportunistic behavior also becomes more likely (Chung and Beamish, 2012). An increase in partner-related risk will increase transaction costs. Because they are faced with higher transaction costs, firms are more likely to organize economic transactions through internal hierarchies rather than using the market mechanism or hybrid mechanisms, such as IJVs. Under these circumstances, firms are thus more likely to internalize transactions by converting their IJV to a fully owned subsidiary (Pangarkar and Klein, 2004). Thus, as the number of partner firms increases, the call option, i.e. the option to acquire the IJV from the other partner(s), becomes more valuable than the option to maintain the IJV. The exercise of the call option through the acquisition of the IJV thus becomes more likely. Accordingly, we formulate the following hypothesis.

H2a. As the number of partners increases, the likelihood that a foreign partner will acquire an IJV increases.

The risk associated with an increase in the number of partners will also increase the likelihood that the firm divests the IJV rather than maintaining the IJV. As in the case of dyadic IJVs, contracts may or may not explicitly stipulate the right of one or more of the partners to buy out the other partners or sell its stake to the other partners. In the absence of such explicit stipulations, however, firms may not be able to buy out multiple partners or may only be able to do so by incurring high costs. This is because obtaining the agreement of an increasing number of partners might be more costly than pulling out of the IJV and setting up a wholly owned operation instead. As a result, the value of the put option should increase with the greater partner-related risk associated with an increase in the number of IJV partners. This assumption is in line with Hennart and Zeng (2002), who stress how the increased transaction costs associated with an increase in the number of IJV partners can increase the likelihood of IJV dissolution. We thus expect the endogenous risk associated with a growing number of IJV partner firms to increase the likelihood of divestment, vis-à-vis the option to maintain the IJV. Accordingly, we formulate the following hypothesis.

$H 2 b$. As the number of partners increases, the likelihood that a foreign partner will divest an IJV increases.

\subsection{The moderating influence of IJV age on the effect of environmental risk and firms' choice of IJV termination mode}

A firm's propensity to acquire an IJV because of a decline in environmental risk will decrease with IJV age because of the relational capital and structural attachment between partners that develop over time. Relational capital creates psychological deterrents to acquiring an IJV, which make firms less likely to "drop" their IJV partner when environmental risk declines. Similarly, structural attachment based on the history of firm-specific investments made since the establishment of the IJV increases with the age of the IJV (Inkpen and Beamish, 1997). If the partners have developed a strong attachment and have invested in their relationship over time, inertia forces may work against intentions to abandon the partners (Inkpen and Beamish, 1997). This growing structural attachment and the associated mutual interdependence between the partners reduce the foreign firm's desire to buy out the local partner(s). Therefore, both relational capital and the structural attachment that develop over time can deter foreign firms from acquiring their IJV, thus mitigating the effect that a decline in environmental risk has on the likelihood that firms will terminate an IJV through acquisition. The degree to which a foreign firm can reduce transaction costs by transitioning from joint to hierarchical coordination - i.e. by acquiring an IJV - declines as relational capital and structural attachment develop over time. Consequently, the increase in the value of the 
call option (i.e. acquisition) resulting from a decline in environmental risk is lower for older IJVs than for younger IJVs. Therefore, a firm's propensity to respond to a decline in environmental risk by acquiring an IJV declines with IJV age. Accordingly, we formulate the following hypothesis:

H3a. IJV age weakens the positive effect of a decline in environmental risk on the likelihood that a foreign firm will acquire an IJV.

Similarly, as an IJV ages, firms become even less likely to respond to a decline in environmental risk by divesting an IJV. This is again due to the relational capital and structural attachment that develop over time, as mentioned above (Inkpen and Beamish, 1997), which reduces the likelihood that firms will divest an IJV. Additionally, the growing relational capital and associated trust between partners means that partners "limit their cognitive efforts. ... when they consider their broader environment" as they increasingly rely on the information provided by their partner(s) (Krishnan et al., 2006: 894-895). Consequently, firms may not react or not react adequately to changes in the environment. The development of relational capital and trust over time may lead to a "buffering" of the effect of a change in the environmental risk on a firm's decision to divest an IJV. Additionally, as an IJV ages, there may also be additional psychological deterrents to IJV divestment related to sunk costs, overconfidence and escalating commitment (Adner and Levinthal, 2004). These considerations might lead firms to ignore or downplay changes in the environment and make it less likely that firms will divest an IJV under declining environmental risk. Accordingly, we formulate the following hypothesis:

$H 3 b$. IJV age strengthens the negative effect of a decline in environmental risk on the likelihood that a foreign firm will divest an IJV.

\subsection{The moderating influence of IJV age on the effect of partner-related risk on firms' choice of IJV termination mode}

Options logic and TCE-based explanations of IJVs suggest that as IJV age increases, the uncertainty regarding partner firms' capabilities and potential opportunistic behavior decreases (Chi and McGuire, 1996; Folta, 1998). This assumption is supported by research on the role of time in the development of relational capital and trust in IJVs (e.g. Kale et al., 2000; Mohr and Puck, 2013). Partner-related risk is endogenous because foreign firms can resolve it by employing monitoring and control mechanisms, introducing specific routines for cooperating with each other or obtaining additional information on their partners $(\mathrm{Lu}$ and Hébert, 2005; Pangarkar and Klein, 2004). As the age of an IJV increases, foreign firms obtain more information on their partners and become more knowledgeable about their partners. Such knowledge and understanding about the partners can improve the foreign firm's ability to predict the partners' future behavior (Lu and Hébert, 2005), which mitigates partner-related risk in multipartner IJVs. Relational capital and the associated decrease in the (perceived) threat of opportunistic partner behavior improve the cost efficiency of the IJV as a governance mechanism compared with a wholly owned subsidiary, that is, the alternative and hierarchical mechanism for organizing transactions (Williamson, 1991). Parkhe (1993: 803) suggests that "[t]he older a relationship, the greater the likelihood it has passed through a critical shakeout period of conflict and influence attempts by both sides." The decrease in partner-related risk that is associated with increasing IJV age will therefore moderate the effect of multipartner risk on the likelihood that foreign firms will exercise the call and put options embedded in their IJVs.

The increase in the value of the call option (i.e. an acquisition) that is caused by multipartner risk is lower for older IJVs. A firm's propensity to respond to higher partnerrelated risk arising from having multiple partners by acquiring an IJV declines as relational
Alternative termination modes of IJVs

1133 
IMR

37,6

\section{4}

capital is developed over time. As an IJV ages, partner-related risk and its associated costs decline as relational capital develops over time. The likelihood that a foreign firm will acquire an IJV in response to the greater risk associated with multipartner IJVs thus declines with IJV age. Accordingly, we formulate the following hypothesis.

$H 4 a$. IJV age weakens the positive effect of an increasing number of IJV partners on the likelihood that a foreign firm will acquire an IJV.

However, a firm's propensity to divest an IJV because of the partner-related risk arising from having multiple partners will decrease because of the relational capital that has developed between the partners over time. The relational capital developed over time reduces conflicts between partners and the need to monitor partners because of the decline in the perceived threat of opportunistic behavior (Chi and McGuire, 1996). As the IJV ages, the partners are likely to develop routines and processes to coordinate and manage the contributions of multiple partners. Because of this reduction in transaction costs over time, the value of the put option relative to the value of the option to maintain the IJV declines as the IJV ages. The likelihood that a foreign firm will divest an IJV because of the endogenous risks associated with a growing number of IJV partners is likely to reduce with IJV age. Accordingly, we formulate the following hypothesis.

H4b. IJV age weakens the positive effect of an increasing number of IJV partners on the likelihood that a foreign firm will divest an IJV.

\section{Methods}

\subsection{Research context and sample}

To test our hypotheses, we decided to examine IJVs in a setting that is characterized by high levels and high variability in exogenous and endogenous risk. This type of environment is particularly found in emerging economies, which tend to promise great opportunities but cause foreign investors to be faced with high levels of risk. We chose the PRC as the context for our study because of the important role that IJVs have traditionally played for foreign investors entering China and because of the significant changes in environmental risk in China over the past decades.

We extracted data on IJVs in the PRC announced between 1985 and 2010 from the Thomson SDC database. We considered IJVs where the foreign partner had at least $10 \%$ ownership and up to $90 \%$ ownership. The SDC database does not provide information about whether or how an IJV was terminated. We thus gathered additional information on the termination modes for a randomly selected set of 2,000 IJVs by conducting searches on other databases, such as LexisNexis, and general web searches. We used data from only quality newspapers or news services. The SDC database provided the dissolution date for 61 of the 2,000 IJVs; we excluded these IJVs. We also excluded IJVs if restrictions on foreign ownership existed at the time of IJV establishment. For the remaining IJVs, we collected information to determine whether they continued to operate, had been acquired by the foreign partner firm, or had been divested by the foreign partner firm. We removed 14 cases in which a foreign firm divested the IJV but established a wholly owned operation in the same sector within one year of divestment. We excluded these cases to ensure that IJV divestment did not reflect increased commitment to the market. Our final sample comprised 459 IJVs [2], of which $110 \mathrm{IJVs}(24.0 \%)$ no longer existed and $349(76.0 \%)$ remained in operation at our cut-off date. Among the 110 terminated IJVs, $62(56.4 \%)$ were divested by the foreign partner, and $48(43.6 \%)$ were bought out/acquired by the foreign firm. Table 3 shows the years the IJVs were acquired or divested. Table 4 gives a breakdown of the age of the surviving IJVs at the end of the time period. 


\begin{tabular}{|c|c|c|c|}
\hline IJV age & Number of divestments & Number of acquisitions & Alternative \\
\hline 1 & 14 & 0 & modes of IIVs \\
\hline 2 & 4 & 1 & \\
\hline 3 & 6 & 3 & \\
\hline 4 & 10 & 5 & \\
\hline 5 & 5 & 7 & \\
\hline 6 & 6 & 3 & 1135 \\
\hline 7 & 1 & 5 & \\
\hline 8 & 1 & 5 & \\
\hline 9 & 3 & 3 & \\
\hline 10 & 2 & 2 & \\
\hline 11 & 3 & 4 & \\
\hline 12 & 1 & 4 & \\
\hline 13 & 2 & 0 & \\
\hline 14 & 2 & 3 & \\
\hline 15 & 0 & 2 & Table 3. \\
\hline 16 & 1 & 1 & Number of acquisitions \\
\hline 17 & 1 & 0 & and divestments by \\
\hline Total & 62 & 48 & IJV age \\
\hline
\end{tabular}

\begin{tabular}{lc}
\hline IJV age & Number of remaining IJVs \\
\hline 3 & 4 \\
4 & 8 \\
5 & 10 \\
6 & 16 \\
7 & 17 \\
8 & 14 \\
9 & 18 \\
10 & 16 \\
11 & 15 \\
12 & 10 \\
13 & 16 \\
14 & 15 \\
15 & 31 \\
16 & 55 \\
18 & 57 \\
19 & 22 \\
20 & 10 \\
24 & 11 \\
Total & 3 \\
\hline
\end{tabular}

In contrast to most previous studies on IJV survival, here, we recoded the $459 \mathrm{IJV}$ s into a panel formation, which was necessary to account for variations in the decline in environmental risk over each IJV's lifetime and thus allowed us to treat the decline in environmental risk as a time-varying variable. For example, we divided an IJV established in 1990 and terminated in 1995 into five observations that captured the five "life periods" of 1990-1991, 1990-1992, 1990-1993, 1990-1994 and 1990-1995. For this IJV, the change in environmental risk may have been positive in the first four periods but negative over the entire period of 1990-1995. 
IMR

37,6

Failing to account for this variation would mean that the change in environmental risk from 1990 to 1995 is used to explain the nontermination of the IJV in 1991, 1992, 1993 and 1994, i.e. events that lie in the past. Because we coded repeated observations for each of the 459 IJVs, our data contained 5,379 observations.

\subsection{Dependent and independent variables}

Our dependent variable, IJV termination mode, takes one of three values: it assumes the value of 0 if the IJV continues to exist at the end of our observation period, the value of 1 if the IJV was divested, and the value of 2 if the IJV was bought out by the foreign firm.

To measure the decline in environmental risk, we use data obtained from the International Country Risk Guide published by the PRS group. These data contain annual assessments of economic, political and financial risks, and higher values indicate higher risk (maximum score: 100). We calculate the decline in environmental risk over the lifetime of an IJV by subtracting one of the following scores from the risk score in the year before the IJV was established. For terminated IJVs, we subtracted the risk score for the year before the IJV was divested or was bought out. For surviving IJVs, we subtract the risk score for the year before our cut-off date, namely, December 31, 2010. We carried out factor analysis on these three indicators (i.e. the decline in economic risk, the decline in political risk and the decline in financial risk) to combine these three individual items into a single variable reflecting the decline in overall environmental risk that foreign firms faced in the PRC. Factor analysis is a commonly used technique to construct a composite index. Nielsen (2007), for example, constructs an overall index of country risk through factor analysis and similarly, Konara and Wei (2019) construct composite indices of language capital and human capital through factor analysis. Various other studies have also used factor analysis to condense the information contained in a set of variables into a smaller set of uncorrelated dimensions (factors) (see, for example, Dong and Glaister, 2006; Zeng et al., 2009). According to Kaiser (1960), factors with an eigenvalue larger than one should be retained. In our case, the eigenvalue of the first principle factor was 1.66, and the eigenvalue of the next (second) principle factor was 0.05 (significantly smaller than one). Therefore, only the first factor satisfies this condition, and thus, we use the first factor from the factor analysis output as the composite variable [3]. Positive values for this variable reflect a decline in risk.

We capture the partner-related risk arising from having multiple partners by the number of partners in the IJV, as is commonly done in the prior literature (e.g. Beamish and Kachra, 2004; Hennart and Zeng, 2005). To measure IJV age, which is our moderating variable, we follow prior research and use the logarithm of the number of years since the establishment of the IJV (Bai et al., 2019).

\subsection{Control variables}

We control for several variables that could affect the risk of IJV dissolution in general and/or the specific risk that a foreign firm will divest or buy out an IJV (Nemeth and Nippa, 2013; Reuer and Zollo, 2005). First, we control for the size of a foreign firm's equity stake (Foreign Partner Stake). Research that applies options logic to IJVs indicates that firms with small equity stakes are more likely to view IJVs as a real option because large initial ownership positions reduce the value of the growth option (Chi and McGuire, 1996; Cuypers and Martin, 2010; Kogut, 1991; Tong et al., 2008). Although options logic does not indicate whether a particular termination outcome is more or less likely if a foreign firm holds a small equity stake, other research proposes that an increasing equity share that is held by a foreign firm reduces the (local) partner's opportunistic behavior, which makes divestment less likely (Dhanaraj and Beamish, 2004). Moreover, a higher equity share has been associated with a higher level of commitment and thus with an increase in the likelihood that a partner will buy 
out its IJV (Dhanaraj and Beamish, 2004). Prior research has provided empirical evidence of both effects (Dhanaraj and Beamish, 2004; Mata and Portugal, 2015).

Prior studies have also argued that the risk of IJV dissolution differs depending on whether the equity is equally shared among partners (see, for instance, Park and Ungson, 1997). Thus, consistent with Park and Ungson (1997), we use a dummy variable (Parity JV) that takes the value of 1 for IJVs in which the partners hold equal equity stakes and the value of 0 for IJVs in which the partners do not hold equal equity stakes.

Research has emphasized that whether partners operate in the same or different sectors affects IJV survival (e.g. Dussauge et al., 2000). Firms with partners that operate in different industries are less likely to replicate the partners' contributions to the IJV. Dussauge et al. (2000) find that some particular link alliances are more likely to be acquired than scale alliances. We followed prior research and used a dummy variable (Intraindustry IJV) to account for IJVs in which the partners operate in the same sector (Yang et al., 2011). We also controlled for the foreign firms' experience by using the total number of prior IJVs that a foreign firm had established in the PRC (Tong et al., 2008). In cases in which an IJV had more than one foreign partner, we calculated the sum of this index across all of the foreign partners. To account for changes in the general investment climate in the PRC, we controlled for whether an IJV was established prior to or after the PRC's entry into the WTO (Post2001).

Prior studies emphasize the relevance of parent size for the survival of subsidiaries (e.g. Dhanaraj and Beamish, 2004). Because the information that is provided by SDC Platinum regarding the size of foreign firms is incomplete and because most firms in our sample are not publicly listed, we adopt the approach that is used by Shi et al. (2014) and control for whether a foreign firm is listed in the Fortune Global 500. We also consider the cultural distance between a foreign partner's home country and China. Cultural distance is a composite variable based on Hofstede's five cultural dimensions [4] and is calculated by using the Euclidean method (Konara and Mohr, 2019). Prior research on the survival of IJVs in the PRC controls for whether an IJV is located in one of the more economically developed coastal regions of the PRC or in a region in the less developed hinterland. Instead of using a dummy variable that is used in most prior research, we capture the differences in economic development and marketization, i.e. the degree of market-oriented reform, including liberalization and privatization, among Chinese provinces by using the National Economic Research Institute (NERI) Index of Marketization. This index was developed by the NERI Reform Foundation and has been used to capture the level of marketization across Chinese provinces (e.g Fan and Wang, 2001; Fan et al., 2010; Li et al., 2009; Zhou et al., 2017). The NERI index is computed using data collected through surveys completed by a large number of enterprises across Chinese provinces (marketization). The Index combines 23 indicators relating to five themes: government-market relations, the non-state enterprise sector, the commodity market, factor markets and the legal framework. Provinces are given scores between 0 and 10 for each of these 23 indicators relative to the best and worst performing provinces. These scores are then aggregated into an index for each year for every province (Gang et al., 2018). We also include industry dummies [5] to account for industry-specific factors that may influence the likelihood or ability of a foreign firm to maintain an IJV or to choose a particular termination mode (Kumar, 2005).

\section{Analyses and results}

\subsection{Analytical approach}

Table 5 shows the descriptive statistics and the correlations among our variables. The correlation coefficients are generally low, except for the correlation coefficient between IJV age and the decline in environmental risk.
Alternative termination modes of IJVs 
IMR

37,6

\section{8}

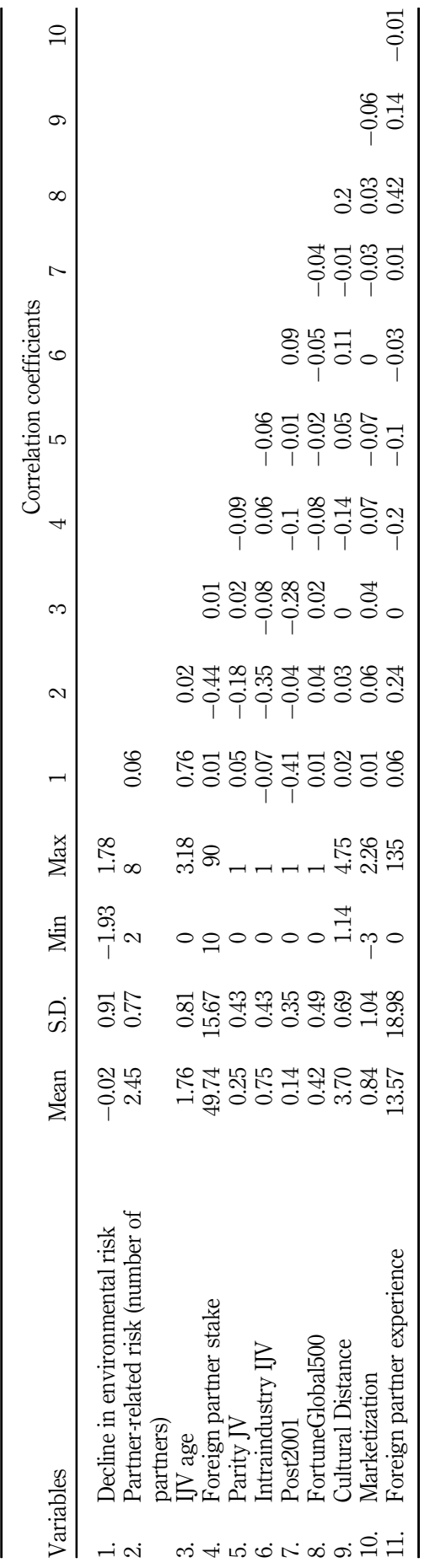

Бे

吉 1

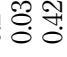

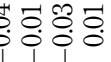

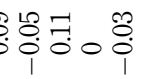

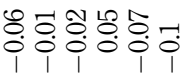

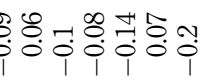

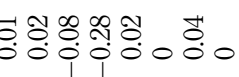

윙 考少

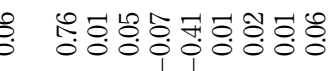

ำ

mo

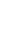

Table 5.

Descriptive statistics and correlation matrix

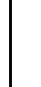


We also carry out a VIF analysis to check for any potential multicollinearity. All the variables have very low VIF scores, ranging between 1.02 and 1.67, confirming that multicollinearity was not a concern.

We assume that the foreign firm makes a decision every year about whether to continue (i.e. exercise the option to defer), buy out the local partner(s) (i.e. exercise the option to acquire), or divest its stake in the IJV (i.e. exercise the option to divest). There are thus two durations, namely, the time until acquisition and the time until divestment. We employ a competing risk hazard approach. Acquisitions are treated as censored when explaining divestment, and divestments are treated as censored when explaining acquisition. According to Esteve-Pérez et al. (2010: 282), survival methods are more appropriate than cross-sectional techniques in the analysis of business exits because survival methods "allow to account for both whether and when an event occurs (i.e. exit), thus controlling for the evolution of the risk of each exit form over time." The key assumption in proportional hazard models is that the hazard ratio for the two events depends only on the covariates and does not depend on time. Because we propose that the effect of a decline in environmental risk on the hazard level depends on IJV age, we relax the proportionality assumption and include an interaction term between our environmental risk variable and the logarithm of IJV age. This approach is recommended when a covariate's influence on the hazard level varies over time, that is, with time-varying coefficients (Ruhe, 2016). To reduce the issue of multicollinearity when including interaction terms, we apply the residual centering procedure (Lance, 1988) to address the correlation between the interaction term and the variable that captures the decline in environmental risk.

\subsection{Results}

Table 6 shows the results of our competing risk analyses. The results for the model testing the direct effects hypothesized in hypotheses $1 \mathrm{a}$ to $2 \mathrm{~b}$ are reported in panel 6.1 . The results for the likelihood that a foreign firm will acquire an IJV are reported in column 1, and the results for the likelihood that a foreign firm will divest an IJV are reported in column 2.

We expected that a decline in environmental risk in the PRC would increase the likelihood that a foreign firm will acquire its IJV (hypothesis 1a). The coefficient for the decline in environmental risk is positive and statistically significant $(1.022, p=0.000)$, providing support for hypothesis 1a. We expected that a decline in environmental risk in the PRC would reduce the likelihood that a foreign firm will divest an IJV (hypothesis 1b). The coefficient for the decline in environmental risk is not statistically significant $(0.207, p=0.167)$; therefore, we do not find support for our hypothesis $1 b$. However, we do find empirical support for this hypothesis after the first year, as explained below, where we discuss the moderating effects of IJV age.

We expected that as the number of partners in an IJV increases, the likelihood that a foreign partner will acquire its IJV in the PRC would increase (hypothesis $2 \mathrm{a}$ ). The coefficient for the number of partners is positive and statistically significant $(0.407, p=0.035)$, providing support for hypothesis 2a. We also expected the likelihood that a foreign firm will divest its IJV in the PRC will increase with an increase in the number of partners in the IJV (hypothesis $2 \mathrm{~b})$. The coefficient for the number of partners is not statistically significant $(0.029, p=0.861)$; therefore, we do not find support for our hypothesis $2 \mathrm{~b}$.

To test hypotheses 3a and 3b, i.e. the moderating effect of IJV age on the effect of a decline in environmental risk on the likelihood that a foreign firm will acquire/divest an IJV, we interacted IJV age with the decline in environmental risk. The results are reported in panel 6.2 in Table 6. The interaction term between the decline in environmental risk and IJV age is negative for acquisition $(-0.303, p=0.041)$. This supports hypothesis $3 \mathrm{a}$, where we argued that IJV age weakens the positive effect of a decline in environmental risk on the likelihood that a foreign firm will acquire an IJV. The interaction term between the decline in
Alternative termination modes of IJVs

1139 
IMR
37,6

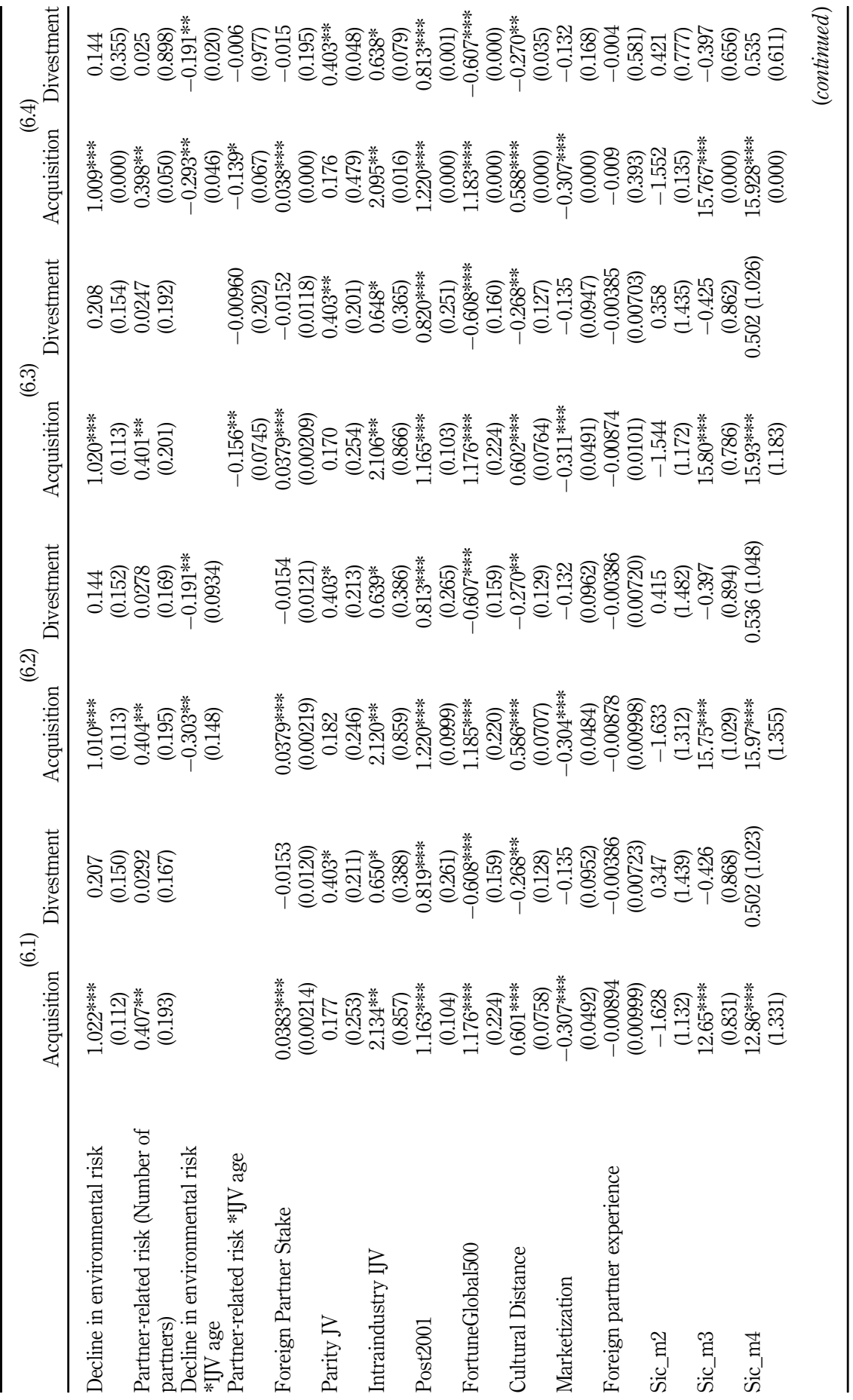

Table 6.

Competing risks analysis 


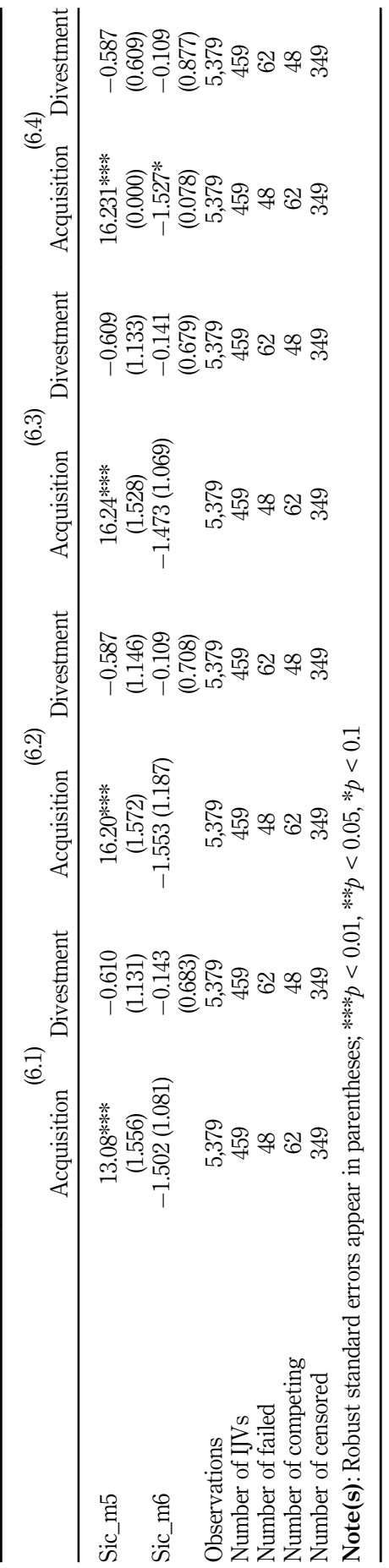

Alternative termination modes of IJVs

1141

Table 6. 
IMR

37,6

1142

environmental risk in the PRC and IJV age is negative for divestment $(-0.191, p=0.040)$. Our results indicate that there is no statistically significant effect in the first year (when IJV age $=1$ ). Because the coefficient for the decline in environmental risk is not statistically significant $(0.144, p=0.346)$, we can consider it statistically not different from zero, which means that the effect of the decline in environmental risk is negative beginning in year two (when IJV age $=2$ ) and that it becomes further negative when IJV age increases. Therefore, a decline in environmental risk reduces the likelihood that a foreign firm will divest an IJV, and this effect becomes stronger with IJV age. These results provide strong support for hypothesis $3 b$.

To test hypotheses $4 \mathrm{a}$ and $4 \mathrm{~b}$ regarding the moderating influence of IJV age on the effect of the number of partners on the likelihood that a foreign firm will acquire/divest an IJV, we interacted IJV age with the number of partners. The results are reported in panel 6.3 in Table 6 . The interaction term between the number of partners and IJV age is negative for acquisition $(-0.156, p=0.036)$. This supports hypothesis $4 \mathrm{a}$, where we argued that IJV age weakens the positive effect of endogenous, partner-related risk on the likelihood that a foreign firm will acquire its IJV in the PRC. The interaction between the number of partners and IJV age was not significant for divestment $(-0.010, p=0.962)$. We thus did not find support for our hypothesis $4 \mathrm{~b}$ in which we expected IJV age to weaken the positive effect of endogenous, partner-related risk on the likelihood that a foreign firm will divest an IJV.

Regarding the control variables, the coefficient for foreign partner stake is positive for acquisition $(0.038, p=0.000$, see panel 6.1 in Table 6 ), which indicates that foreign partners with larger stakes in their IJVs are more likely to buy out their IJVs in the PRC. The coefficient for parity IJV is positive for divestment $(0.403, p=0.056)$ and indicates that foreign firms in the PRC are more likely to divest equally shared IJVs than to divest IJVs in which they hold either a minority or majority stake. The coefficient for intraindustry IJV is positive for both acquisition $(2.134, p=0.013)$ and divestment $(0.650, p=0.094)$, which indicates that foreign firms are more likely to buy out than sell off related IJVs in the PRC. The coefficient for Post2001, accounting for the PRC's entry into the WTO in 2001, is positive for both acquisition (1.163, $p=0.000)$ and divestment $(0.819, p=0.002)$. This finding provides evidence of increased acquisition and divestment activity in the post-2001 era. The coefficient of FortuneGlobal500 is positive for acquisition $(1.176, p=0.000)$ but negative for divestment $(-0.608, p=0.000)$. In the PRC, foreign firms in this group are thus more likely to buy out their IJVs and less likely to divest their IJVs. The coefficient for cultural distance is positive for acquisition $(0.601, p=0.000)$, indicating that foreign firms from culturally distant countries are more likely to acquire their IJVs in the PRC. It is negative for divestment $(-0.268, p=0.037)$, indicating that foreign firms from culturally distant countries are less likely to divest IJVs in the PRC. The coefficient for the marketization level of the Chinese province in which an IJV is located $(-0.307, p=0.000)$ shows that foreign firms are less likely to buy out IJVs in marketized provinces.

Finally, our results show that IJV termination through acquisition is more likely in the manufacturing sector (SIC 20-39), the transportation, communications, electric, gas, and sanitary services sector (SIC 40-49), and in the wholesale and retail trade (SIC 50-59). Similarly, the descriptive statistics show that whereas termination through divestment took place across all sectors, acquisitions of IJVs took place only in the manufacturing sector (SIC 20-39), the transportation, communications, electric, gas, and sanitary services sector (SIC 40-49), and in the wholesale and retail trade sector (SIC 50-59). We also find that in the manufacturing sector (SIC 20-39) and the wholesale and retail trade (SIC 50-59) sectors, a similar percentage of IJVs was terminated through divestment and through acquisition; however, in the transportation, communications, electric, gas, and sanitary services sector (SIC 40-49), IJVs were more likely to be terminated through divestment than through acquisition (please see Table 7). 
6.3 Robustness checks

To check the robustness of our results, we carried out additional analyses. First, prior research has suggested the possibility of a so-called honeymoon period [6], i.e. the initial period of an IJV's existence during which the termination of an IJV is less likely. We tested this possibility by excluding IJVs that existed for less than two years from our analyses and rerunning our analyses. The results of these analyses are consistent with the results based on our entire sample, and there does not seem to be an effect of a potential honeymoon period in our sample. Second, we used an alternative measure of external risk by carrying out factor analyses with orthogonal rotation (varimax rotation) and with oblique rotation (promax rotation) of the factor loadings matrix. All our results remained intact. We also used an alternative measure of external risk by averaging our three measures of risk rather than using factor analysis. The results remained consistent. We replaced the 5-dimensional measure of cultural distance with the 6-dimensional measure of cultural distance (Hofstede et al., 2010) as a further robustness check, and our results remained largely intact. Finally, we carried out a robustness test by including both interaction terms together (panel 6.4 in table 4) and the results remain intact.

\section{Discussion and implications}

Combining options logic with TCE arguments, we developed hypotheses regarding the effects of a decline in environmental risk and partner-related risk arising from having multiple partners on the likelihood that firms will either acquire or divest IJVs. We expected that a decline in environmental risk in the PRC would increase the likelihood that foreign firms will acquire their IJVs (hypothesis 1a). Our results provide support for this hypothesis. This finding is also consistent with prior research that draws on options logic to study the effects of changes in market uncertainty on firms' decisions on whether to acquire JVs (Kogut, 1991). Although Kogut (1991) focuses on favorable economic shocks, i.e. short-term changes in external uncertainty, our results emphasize the role of reduced environmental (i.e. political, economic and financial) risks over the entire lifetime of an IJV. In contrast to Kogut (1991), we highlight the role of changes in the broader environment. We suggest that such changes are particularly pronounced in most emerging economies, including the PRC. Although they do not draw on options logic, Puck et al. (2009) similarly find that foreign firms that perceive no decline in external uncertainty are less likely to convert their IJVs into wholly owned subsidiaries. Puck et al. (2009) draw on TCE to argue that a reduction in uncertainty induces firms to acquire their IJVs in the PRC. If a decline in external uncertainty is treated as a decline in external environmental risk, our results are consistent with their findings. We complement this prior research further by differentiating termination outcomes and stressing the contingent nature of the effects of changes in environmental risk.

\begin{tabular}{lccc}
\hline & $\begin{array}{c}\text { Number of } \\
\text { divestments (\%) }\end{array}$ & $\begin{array}{c}\text { Number of } \\
\text { acquisitions (\%) }\end{array}$ & $\begin{array}{c}\text { Total number } \\
\text { of IJVs }\end{array}$ \\
\hline SIC M2. Mining and construction (SIC 10-17) & 25.00 & 0.00 & 4 \\
SIC M3. Manufacturing (SIC 20-39) & 12.41 & 11.19 & 411 \\
SIC M4. Transportation, communications, & 35.29 & 5.88 & 17 \\
electric, gas, and sanitary services (SIC 40-49) & 10.00 & 10.00 & 10 \\
SIC M5. Wholesale and retail trade (SIC 50-59) & 20.00 & 0.00 & 10 \\
SIC M6. Finance, insurance, and real estate & 14.29 & 0.00 & 7 \\
(SIC 60-67) & 13.51 & 10.46 & 459 \\
SIC M7. Services (SIC 70-89) & & &
\end{tabular}

Alternative termination modes of IJVs

1143 
IMR

37,6

1144

We argued that a decline in environmental risk has a negative effect on foreign firms' propensity to divest IJVs (hypothesis $1 \mathrm{~b}$ ). Our findings reveal the existence of such a negative effect beginning in the second year of an IJV's life. We argued that as environmental risk in the PRC declines, the option to divest an IJV becomes less valuable, and thus, firms are less likely to exercise this option. Our findings contrast with prior research that emphasizes the role of IJVs in mitigating substantial environmental hazards (Henisz, 2000); this prior research implies that as environmental hazards decline, a firm's need to mitigate hazards through an IJV also declines. Prior research thus suggests that a reduction in risk would increase rather than decrease the likelihood of IJV divestment. The discrepancy between the results of this study and prior results is due to the fundamentally different role that uncertainty plays in real options logic as opposed to other theoretical frameworks, including for example, institutional theory.

Taken together, our findings regarding hypotheses $1 \mathrm{a}$ and $1 \mathrm{~b}$ underscore the different roles that a decline in environmental risk can play in firms' decisions on whether to buy out or divest their IJVs in the PRC. This insight is important for research on IJV termination. Although it acknowledges the different ways in which a firm can terminate an IJV, research on IJV termination has traditionally treated IJV dissolution as an undifferentiated event and explored the factors that drive dissolution in general, without accounting for different types of termination. Nemeth and Nippa (2013) suggest that the lack of attention to differentiation makes it difficult to compare the various studies on the determinants of IJV dissolution. The findings of past research on IJV dissolution, particularly research that equates dissolution with failure, must be interpreted with this distinction in mind because divestments and acquisitions may indicate different levels of IJV success (Hennart and Zeng, 2002; Kumar, 2005; Reuer and Zollo, 2005).

We further hypothesized that higher partner-related risk arising from having multiple partners would increase the likelihood that a foreign firm will either exercise the call option that is embedded in an IJV by acquiring the IJV (hypothesis 2a) or the put option that is embedded in an IJV by divesting the IJV (hypothesis $2 \mathrm{~b}$ ). We suggested that the existence of multiple partners is a central source of endogenous risk in IJVs in the PRC, where multipartner IJVs are more common. However, we found support only for hypothesis 2a. Our findings contrast with prior research that does not differentiate the termination modes and provides mixed evidence on the effect of multipartner risk (Beamish and Kachra, 2004; Chung and Beamish, 2012). By differentiating the termination modes, we show that foreign firms in the PRC are more likely to acquire IJVs with higher partner-related risk but do not choose to divest IJVs with higher partner-related risk. We suggest that this is because partner-related risk is endogenous and not exogenous; i.e. there is no incentive for the foreign partner to abandon the PRC. Therefore, the foreign partner may prefer the call option over the put option.

We also found support for the expected weakening over time of the positive effect of a decline in environmental risk on a firm's decision on whether to acquire an IJV (hypothesis 3a). Our expectation was based on the role that behavioral uncertainty plays in the choice of governance structures according to TCE (Williamson, 1991). Based on TCE logic, we suggested that a change in governance structure from an IJV to a wholly owned operation through the acquisition of an IJV in response to a decline in environmental risk becomes a less favorable alternative as behavioral uncertainty decreases and relational capital increases. Because behavioral uncertainty declines over time, we expected the effect of a decline in environmental risk in the PRC on the likelihood of IJV acquisition to decline with IJV age. In addition, we provide evidence showing that the negative effect of a decline in environmental risk on firms' propensity to divest IJVs becomes stronger as IJV age increases (hypothesis $3 \mathrm{~b}$ ). We argued that the relational capital that develops as IJV partners work together over time affects the degree to which a decline in environmental risk affects how firms terminate their IJVs in the PRC. Prior research underscores the role of relational capital 
and the associated decline in perceived partner-related uncertainty in the formation and structuring of strategic alliances (Dyer, 1997; Gulati, 1998; Gulati and Singh, 1998). We supplement prior research by providing evidence that relational capital also has an indirect effect on how firms terminate alliances. The empirical support for these hypotheses underscores the usefulness of combining TCE-based reasoning with options logic when explaining a firm's choice of IJV termination mode.

Our results provide empirical support for the expected weakening over time of the positive effect of the partner-related risk associated with an increase in the number of IJV partners on the likelihood that a foreign firm will acquire an IJV (hypothesis 4a). We argued that the relational capital developed as an IJV ages will compensate for greater risk associated with a larger number of partners. However, we did not find support for hypothesis $4 \mathrm{~b}$, where we argued that the positive effect of partner-related risk on the likelihood that a foreign firm will divest an IJV weakens over time. There may thus be factors that increase, rather than reduce, the likelihood that IJVs will be terminated over time, thus cancelling out the direct effect of IJV age on IJV dissolution. Chung and Beamish (2012) suggest that the effect of multipartner complexity on the termination of IJVs depends on whether the IJV has already undergone some form of structural change. Assuming that older IJVs are more likely to have undergone structural change, this would imply that older IJVs are more likely to be terminated than younger IJVs. Prior research that investigates how the risk of alliance dissolution varies over the lifetime of an alliance has yielded inconsistent findings (e.g. Beamish and Kachra, 2004; Hennart and Zeng, 2002; Mohr et al., 2016a, b; Park and Russo, 1996). Although we do not investigate the direct effect of IJV age on the likelihood of various IJV termination outcomes, our findings for hypotheses $4 \mathrm{a}$ and $4 \mathrm{~b}$ suggest that accounting for different termination outcomes may explain the inconsistent research results that have been obtained thus far.

Overall, while we found support for the hypothesized effects on foreign firms' acquisition of their IJVs in the PRC, three of the hypotheses explaining firms' divestment of IJVs based on exogenous and endogenous risk were not empirically supported, indicating that divestment may be driven by exogenous or endogenous risks that are not captured in our explanatory variables. For example, rather than the changes in overall environmental risk in the PRC that we considered in our study, dissolution may be caused by changes in the industry-specific environment. Prior research has highlighted the role of industry-level changes in IJV dissolution (Hennart et al., 1998; Kogut, 1991). In addition, our use of the number of partners to proxy for the level of endogenous risk in an IJV is likely to capture not only the additional risks associated with an increase in the number of partners but also the additional benefits of having access to a more diverse set of partner resources and capabilities, which is of particular importance in the case of the PRC (Chung and Beamish, 2012; Mohr et al., 2016a, b). The latter may positively affect the likelihood of acquisition but reduce the likelihood that a foreign firm wants to divest its IJV in the PRC, thus compensating for the effect of greater levels of endogenous risk. Other indicators may better reflect the level of endogenous risk. In particular, prior research has highlighted the greater behavioral uncertainty and likelihood of conflict associated with parity IJVs (Killing, 1983). Our findings underline this logic, given that we find statistically significant positive coefficients in all our models for the effect of equal equity stakes (parity IJV) on the likelihood that firms divest an IJV (please see Table 6).

\subsection{Theoretical implications}

Recent research has begun to investigate and differentiate among the drivers of different IJV termination modes (Mata and Portugal, 2015; Puck et al., 2009). Thus far, however, our understanding of what drives firms to terminate an IJV by acquiring operations rather than divesting operations remains limited. Our study contributes to this understanding by complementing options logic with TCE logic to highlight the effects of exogenous and endogenous risk on a firm's decision to buy out or divest an IJV. 
IMR

37,6

1146

Options logic specifically emphasizes the role of (the changes in) exogenous risk (Ahsan and Musteen, 2011; Folta, 1998), but the questions of why and when a firm decides to exercise the call (acquisition) or put (divestment) option contained in their IJVs have received relatively little attention. By incorporating insights from TCE logic, we highlight how the effects of exogenous and endogenous risk on the value of different options embedded in IJVs - and thus the likelihood of different IJV termination outcomes - varies over time. Complementing options logic with TCE arguments also highlights IJV age as a boundary condition when options logic is applied to explain firms' choice of IJV termination mode. We thus contribute to the development of options logic by showing that the relationship implied by options logic is complemented by direct and moderating effects that are explained by TCE.

\subsection{Managerial implications}

The findings of our study have implications for managerial practice. In particular, framing IJVs as real options suggests that firms may use such ventures to "test" overseas markets before committing to particular ways to serve a particular market. This is particularly the case when the development of overseas markets is uncertain, as it allows firms to reduce the downside risk associated with an overseas investment. Managers should continuously monitor the development of this uncertainty when making decisions regarding whether or how to terminate an IJV. Our findings show that once environmental risk declines, firms are likely to terminate their IJVs by acquiring them. Our findings also show that over time (from the second year onwards), a decline in environmental risk reduces the likelihood that a foreign firm will divest an IJV, and this effect becomes stronger with IJV age.

Our findings suggest that in the case of multipartner IJVs, which are associated with greater levels of partner-related risk, firms are more likely to acquire an IJV than divest it. We suggest that this may be due to the particular resource contribution of the partners that a firm is more likely to maintain if it acquires the IJV instead of divesting it. Firms that consider the termination of an IJV should thus assess the consequences of different types of termination for their access to particular resources provided by their IJV partner(s).

Our study suggests that the development of both environmental risk in a market as well as partner-related risk, and their interaction with the age of an IJV influence how firms use the options provided by an international joint venture. Specifically, managers should be aware of the role of relational capital developed in the course of a collaborative venture. Prior research has highlighted the positive effects of relational capital on IJV survival (Park and Russo, 1996; Slater and Robson, 2012). However, our findings indicate that there are possible downsides of the development of such relational capital, as it might lead to a decreased sensitivity to environmental changes. Managers need to be aware that relational capital might affect their perception of and reactions to changes in both environmental and partner-related risk. Managers thus need to be aware of the role that relational capital accrued over time plays in decisions on whether and how to terminate an IJV.

\subsection{Limitations and directions for further research}

Our study has several limitations that open various directions for future research. First, we did not obtain data to capture other factors that may influence firms' decisions to acquire or divest IJVs. For example, we did not obtain data on firms' strategic priorities, which may change after IJV establishment (Koza and Lewin, 1998) and may affect the likelihood of different termination outcomes. Research on business exits emphasizes firm performance as a determinant of firm exits. Peel and Wilson (1989), for example, examine firm solvency and its effect on the survival, merger or failure of firms. The database that we used does not provide any information about IJV performance. Future research should use survey data to capture and account for the effects of IJV performance. Additionally, we did not obtain 
information on the foreign firms' experience in the PRC at the time of establishing a particular IJV other than the experience they obtained through operating other IJVs in the country. Finally, we did not obtain any information on the buyer in cases where an IJV was sold, and the likelihood of divestment may be affected by the existence and nature of potential buyers. It seems that future research examining these additional factors would be worthwhile [7].

Second, consistent with much of the prior research that draws on options logic, we focus on the foreign firms' perspective without accounting for the perspective of the local firm (e.g. Cuypers and Martin, 2010; Kumar, 2005; Reuer and Tong, 2005). Although there have been efforts to account for all partners' assessments of their respective options, such work remains conceptual (Buckley and Casson, 1998; Chi, 2000). Moreover, prior research has accounted for the perspectives of both partners (e.g. Mata and Portugal, 2015), but this research does not apply options logic. Future research should thus attempt to examine the termination outcomes of IJVs, taking into account all of the involved parties' perspectives. This may require in-depth case studies of terminated IJVs given the difficulties in obtaining data on the characteristics and goals of all partners involved in IJVs.

Third, the options that we consider are complete divestment and complete acquisition of IJVs. We do not consider changes in equity shares. Although they do not focus on explaining JV termination modes, Folta and Miller (2002) explain sequential increases in minority investments made by firms outside the biotechnology industry in potential acquisition targets in the biotechnology industry. Similarly, Shi and Iriyama (2010) analyze how the initial design of an equity partnership influences its subsequent ownership evolution. We investigated our sample for incremental changes in ownership over time but found very little evidence of such changes. Accordingly, we treated acquisitions and divestments as discrete events. Similarly, we did not account for the fact that firms may have divested multiple IJVs in a given year. Future research should provide a more finely grained analysis of the paths that lead firms to acquire or divest IJVs and take into account the effect of concurrent (dis-) investments in a particular country.

Finally, we studied foreign firms' IJVs in the Peoples' Republic of China. The environment in the PRC is arguably more dynamic than in Western developed countries or Japan. In such circumstances, both IJVs as operation modes for foreign firms as well as the termination of these IJVs in response to changes in exogenous risk are thus likely to be of particular importance. Our findings are thus most likely to be relevant for foreign firms operating in countries with similar conditions. In particular, conditions in emerging or developing economies appear to be similar to those in the PRC, although there is of course significant variety across emerging economies (Meyer, 2015). Future research should thus explore whether the relationships proposed in this study hold in other emerging economies or in developed economies; such an analysis would provide a more conservative test of our hypotheses, given their comparatively lower environmental dynamism. IJVs in the PRC are more likely to involve multiple partners due to the particularly strong governmental involvement in economic activity, which frequently leads to the participation of statecontrolled actors (Mohr et al., 2016a, b). Both of the drivers that we investigated in our study, i.e. the change in environmental risk and the risk associated with an increasing number of IJV partners, thus seem of particular importance for foreign firms in the PRC. Future empirical studies on the role of these factors in countries in which multipartner IJVs are comparatively less common would thus provide a more conservative test of the suggested relationship and examine the degree to which the effect might be specific to the particular context of IJVs in the PRC. Similarly, we studied IJVs that were established between 1985 and 2010, and we determined whether they were still in operation or had been terminated by the end of 2014 . We suggested that the general effect of changes in environmental risk on IJV termination will exist in other time periods as well, although the magnitude of such changes may of course differ. Future research could examine the effects of changes in environmental risk on IJV

\section{Alternative termination modes of IJVs}

1147 
IMR

37,6

termination, specifically in cases in which such changes were less pronounced than in the PRC from 1985 to 2014 [8].

\section{Conclusion}

Our study was motivated by the lack of explanations of the conditions under which firms divest or buy out IJVs. We provide an explanation that combines options logic with insights from TCE and relates a decline in environmental risk and partner-related risk to firms' choices of IJV termination modes. We argue that a decline in environmental risk increases the likelihood that firms will terminate IJVs through acquisition but reduces the likelihood that firms will terminate IJVs through divestment. We also find that partner-related risk increases the likelihood that firms will terminate IJVs through acquisition but does not affect the likelihood that firms will terminate IJVs through divestment. Additionally, we hypothesize and find that the effect of a decline in environmental risk on both types of IJV termination varies with the age of an IJV. Finally, we find that the positive effect of multipartner risk on the likelihood that a foreign firm will acquire an IJV weakens over time.

\section{Notes}

1. Uncertainty and risk have been distinguished by the fact that in contrast to the former, the latter can be measured and often be attributed to particular sources (Müllner, 2016). In our empirical setting, we measure the risk arising from particular sources. We therefore use the terms uncertainty and risk interchangeably, which is also the case in much of the research on firm internationalization (Liesch et al., 2011).

2. The foreign partners of these IJVs were from 29 countries: Australia, Belgium, Brazil, Canada, the Cayman Islands, Colombia, the Czech Republic, Denmark, Finland, France, Germany, Hong Kong, India, Ireland, Italy, Japan, Malaysia, the Netherlands, New Zealand, the Philippines, Singapore, South Korea, Sweden, Switzerland, Taiwan, Thailand, the UK, the United Arab Emirates and the USA.

3. We carried out factor analysis without rotation, but ran the analysis with rotation as a robustness test. The results of these analyses are reported in the section on the robustness tests.

4. We also use the six dimension framework proposed by Hofstede et al. (2010) as an alternative measure for cultural distance as a robustness check.

5. The industry dummies were as follows: SIC M1. Agriculture, forestry, and fishing (SIC 01-07); SIC M2. Mining and construction (SIC 10-17); SIC M3. Manufacturing (SIC 20-39); SIC M4. Transportation, communications, electric, gas, and sanitary services (SIC 40-49); SIC M5. Wholesale and retail trade (SIC 50-59); SIC M6. Finance, insurance, and real estate (SIC 60-67); and SIC M7. Services (SIC 70-89).

6. We would like to thank one of the anonymous reviewers for highlighting the possibility of a honeymoon period.

7. We would like to thank the anonymous reviewers for highlighting this issue.

8. We would like to thank one of the anonymous reviewers for pointing out this issue.

\section{References}

Adner, R. and Levinthal, D.A. (2004), "What is not a real option: considering boundaries for the application of real options to business strategy", Academy of Management Review, Vol. 29, pp. 74-85.

Ahsan, M. and Musteen, M. (2011), "Multinational enterprises' entry mode strategies and uncertainty: a review and extension”, International Journal of Management Reviews, Vol. 13, pp. 376-392. 
Ali, T. and Larimo, J. (2016), "Managing opportunism in international joint ventures: the role of structural and social mechanisms", Scandinavian Journal of Management, Vol. 32, pp. 86-96.

Bai, X., Chang, J. and Li, J.J. (2019), "How do international joint ventures build legitimacy effectively in emerging economies? CSR, political ties, or both?", Management International Review, Vol. 59, pp. 387-412.

Barkema, H.G. and Vermeulen, F. (1997), "What differences in the cultural background of partners are detrimental for international joint ventures", Jounal of International Business Studies, Vol. 28, pp. 845-864.

Beamish, P.W. and Kachra, A. (2004), "Number of partners and JV performance", Journal of World Business, Vol. 39, pp. 107-120.

Brouthers, K.D., Brouthers, L.E. and Werner, S. (2003), "Transaction cost-enhanced entry mode choices and firm performance", Strategic Management Journal, Vol. 24, pp. 1239-1248.

Brouthers, K.D., Brouthers, L.E. and Werner, S. (2008), "Real options, international entry mode choice and performance", Journal of Management Studies, Vol. 45, pp. 936-960.

Buckley, P.J. and Casson, M.C. (1998), "Models of the multinational enterprise", Journal of International Business Studies, Vol. 29, pp. 21-44.

Chi, T. (2000), "Option to acquire or divest a joint venture”, Strategic Management Journal, Vol. 21, pp. 665-687.

Chi, T. and McGuire, D. (1996), "Collaborative ventures and the value of learning: integrating the transaction cost and strategic option perspectives on the choice of market entry modes", Journal of International Business Studies, Vol. 27, pp. 285-307.

Chung, C.C. and Beamish, P. (2012), "Multi-party international joint ventures: multiple post-formation change processes", Journal of World Business, Vol. 47, pp. 648-663.

Chung, C.C., Lee, S.H., Beamish, P.W., Southam, C. and Nam, D. (2013), "Pitting real options theory against risk diversification theory: international diversification and joint ownership control in economic crisis", Journal of World Business, Vol. 48, pp. 122-136.

Cuypers, I.R.P. and Martin, X. (2010), "What makes and what does not make a real option? A study of equity shares in international joint ventures", Journal of International Business Studies, Vol. 41, pp. 47-69.

Dhanaraj, C. and Beamish, P.W. (2004), "Effect of equity ownership on the survival of international joint ventures", Strategic Management Journal, Vol. 25, pp. 295-305.

Dong, L. and Glaister, K.W. (2006), "Motives and partner selection criteria in international strategic alliances: perspectives of Chinese firms", International Business Review, Vol. 15, pp. 577-600.

Dussauge, P., Garrette, B. and Mitchell, W. (2000), "Learning from competing partners: outcomes and durations of scale and link alliances in Europe, North America and Asia", Strategic Management Journal, Vol. 21, pp. 99-126.

Dyer, J.H. (1997), "Effective Interfirm Collaboration. How firms minimize transaction costs and maximize transaction value", Strategic Management Journal, Vol. 18, pp. 535-556.

Engel, D., Procher, V. and Schmidt, C.M. (2013), "Does firm heterogeneity affect foreign market entry and exit symmetrically? Empirical evidence for French firms", Journal of Economic Behavior and Organization, Vol. 85, pp. 35-47.

Esteve-Pérez, S., Sanchis-Llopis, A. and Sanchis-Llopis, J. (2010), “A competing risks analysis of firms' exit”, Empirical Economics, Vol. 38, pp. 281-304.

Everett, J. and Watson, J. (1998), "Small business failure and external risk factors", Small Business Economics, Vol. 11, pp. 371-390.

Fan, G. and Wang, X. (2001), NERI Index of Marketization of China's Provinces, Economics Science Press, Beijing.
Alternative termination modes of IJVs 
IMR

37,6

1150

Fan, G., Wang, X. and Zhu, H. (2010), "NERI index of marketization of China's provinces”, Report on the Relative Process of Marketization of Each Region in China, Economics Science Press.

Folta, T.B. (1998), "Governance and uncertainty: the tradeoff between administrative control and commitment", Strategic Management Journal, Vol. 19, pp. 1007-1028.

Folta, T.B. and Leiblein, M.J. (1994), "Technology acquisition and the choice of governance by established firms. Insights from opinion theory in a multinomoal logit model", Academy of Management Best Papers Proceedings, Academy of Management, Briarcliff Manor, NY, USA, pp. 27-31.

Folta, T.B. and Miller, K.D. (2002), "Real options in equity partnerships", Strategic Management Journal, Vol. 23, pp. 77-88.

Fong, C.M., Lee, C.L. and Du, Y. (2014), "Consumer animosity, country of origin, and foreign entrymode choice: a cross-country investigation”, Journal of International Marketing, Vol. 22, pp. $62-76$.

Freeman, J., Carroll, G.R. and Hannan, M.T. (1983), "The liability of newness: age dependence in organizational death rates", American Sociological Review, Vol. 48, pp. 692-710.

Gang, F., Ma, G. and Wang, X. (2018), "Marketisation in China from 1997 to 2014: achievements and contribution to growth", in Garnaut, R., Song, L. and Fang, C. (Eds.), China's 40 yrs of Reform and Development: 1978-2018, ANU Press, The Australian National University, Canberra, pp. 257-269.

Gulati, R. (1998), “Alliances and networks”, Strategic Management Journal, Vol. 19, pp. 293-317.

Gulati, R. and Singh, H. (1998), "The architecture of cooperation. Managing coordination costs and appropriation concerns in strategic alliances”, Administrative Science Quarterly, Vol. 43, pp. 781-814.

Harrigan, K.R. (1985), Strategies for Joint Ventures, Lexington Books, Lexington, Mass.

He, W., Boateng, A. and Ring, P. (2019), "Motives, choice of entry mode, and challenges of bank internationalization: evidence from China", Thunderbird International Business Review, Vol. 61, pp. 897-909.

Henisz, W. (2000), "The institutional environment for multinational investment", Journal of Law, Economics, and Organization, Vol. 16, pp. 334-364.

Hennart, J.F. (1988), “A transaction costs theory of equity joint ventures”, Strategic Management Journal, Vol. 9, pp. 361-374.

Hennart, J.F. and Zeng, M. (2002), “Cross-cultural differences and joint venture longevity”, Journal of International Business Studies, Vol. 33, pp. 699-716.

Hennart, J.F. and Zeng, M. (2005), "Structural determinants of joint venture performance”, European Management Review, Vol. 2, pp. 105-115.

Hennart, J.F., Kim, D.J. and Zeng, M. (1998), "The impact of joint venture status on the longevity of Japanese stakes in U.S. manufacturing affiliates”, Organization Science, Vol. 9, pp. 382-395.

Hofstede, G., Hofstede, G.J. and Minkov, M. (2010), Cultures and Organizations, 3rd ed., Software of the Mind, McGraw-Hill, New York.

Inkpen, A.C. and Beamish, P.W. (1997), "Knowledge, bargaining power, and the instability of international joint ventures", Academy of Management Review, Vol. 22, pp. 177-202.

Kaiser, H.F. (1960), "The application of electronic computers to factor Analysis", Educational and Psychological Measurement, Vol. 20, pp. 141-151.

Kale, P., Singh, H. and Perlmutter, H. (2000), "Learning and protection of proprietary assets in strategic alliances: building relational capital", Strategic Management Journal, Vol. 21, pp. 217-237.

Killing, J.P. (1983), Strategies for Joint Venture Success, Croom Helm, London/ Canberra. 
Kogut, B. (1988a), "Joint Ventures. Theoretical and empirical perspectives", Strategic Management Journal, Vol. 9, pp. 319-332.

Kogut, B. (1988b), “A study of the life cycle of joint ventures”, Management International Review, Vol. 28, pp. 39-52.

Kogut, B. (1989), "The stability of joint ventures: reciprocity and competitive rivalry", The Journal of Industrial Economics, Vol. 38, pp. 591-612.

Kogut, B. (1991), "Joint ventures and the option to expand and acquire", Management Science, Vol. 37, pp. 19-33.

Konara, P. and Mohr, A. (2019), "Why we should stop using the Kogut and Singh index", Management International Review, Vol. 59, pp. 335-354.

Konara, P. and Wei, Y. (2019), "The complementarity of human capital and language capital in foreign direct investment”, International Business Review, Vol. 28, pp. 391-404.

Koza, M.P. and Lewin, A.Y. (1998), "The co-evolution of strategic alliances", Organization Science, Vol. 9, pp. 255-264.

Krishnan, R., Martin, X. and Noorderhaven, N.G. (2006), "When does trust matter to alliance performance?”, Academy of Management Journal, Vol. 49, pp. 894-917.

Kumar, M.V.S. (2005), "The value from acquiring and divesting a joint venture: a real options approach", Strategic Management Journal, Vol. 26, pp. 321-331.

Lance, C.E. (1988), "Residual centering, exploratory and confirmatory moderator analysis, and decomposition of effects in path models containing interactions", Applied Psychological Measurement, Vol. 12, pp. 163-175.

Li, K., Yue, H. and Zhao, L. (2009), "Ownership, institutions, and capital structure: evidence from China”, Journal of Comparative Economics, Vol. 37, pp. 471-490.

Liesch, P.W., Welch, L.S. and Buckley, P.J. (2011), "Risk and uncertainty in internationalisation and international entrepreneurship studies", Management International Review, Vol. 51, pp. 851-873.

Lu, J.W. and Hébert, L. (2005), "Equity control and the survival of international joint ventures: a contingency approach", Journal of Business Research, Vol. 58, pp. 736-745.

Madanoglu, M., Alon, I. and Shoham, A. (2017), "Push and pull factors in international franchising", International Marketing Review, Vol. 34, pp. 29-45.

Makino, S. and Beamish, P.W. (1998), "Performance and survival of joint ventures with nonconventional ownership structures", Journal of International Business Studies, Vol. 29, pp. 797-818.

Mata, J. and Portugal, P. (2015), "The termination of international joint ventures: closure and acquisition by domestic and foreign partners", International Business Review, Vol. 24, pp. 677-689.

Meschi, P.X. (2005), "Environmental uncertainty and survival of international joint ventures: the case of political and economic risk in emerging countries", European Management Review, Vol. 2, pp. 143-152.

Meschi, P.X. and Riccio, E.L. (2008), "Country risk, national cultural differences between partners and survival of international joint ventures in Brazil", International Business Review, Vol. 17, pp. 250-266.

Meschi, P.X. and Wassmer, U. (2013), "The effect of foreign partner network embeddedness on international joint venture failure: evidence from European firms' investments in emerging economies", International Business Review, Vol. 22, pp. 713-724.

Meschi, P.X., Norheim-Hansen, A. and Riccio, E.L. (2017), "Match-making in international joint ventures in emerging economies: aligning asymmetric financial strength and equity stake", Management International Review, Vol. 57, pp. 411-440.

Alternative termination modes of IJVs

$-$ 
IMR

37,6

Meyer, K.E. (2015), "Context in management research in emerging economies”, Management and Organization Review, Vol. 11, pp. 369-377.

Mohr, A.T. and Puck, J. (2013), "Revisiting the trust-performance link in strategic alliances", Management International Review, Vol. 53, pp. 269-289.

Mohr, A., Wang, C. and Fastoso, F. (2016a), "The contingent effect of state participation on the dissolution of international joint ventures: a resource dependence approach", Journal of International Business Studies, Vol. 47, pp. 408-426.

Mohr, A., Wang, C. and Goerzen, A. (2016b), "The impact of partner diversity within multiparty international joint ventures", International Business Review, Vol. 25, pp. 883-894.

Müllner, J. (2016), "From uncertainty to risk-a risk management framework for market entry", Journal of World Business, Vol. 51, pp. 800-814.

Nemeth, A. and Nippa, M. (2013), "Rigor and relevance of IJV exit research", Management International Review, Vol. 53, pp. 449-475.

Nielsen, B.B. (2007), "Determining international strategic alliance performance: a multidimensional approach", International Business Review, Vol. 16, pp. 337-361.

Nippa, M. and Reuer, J.J. (2019), "On the future of international joint venture research", Journal of International Business Studies, Vol. 50, pp. 555-597.

Pangarkar, N. and Klein, S. (2004), "The impact of control on international joint venture performance: a contingency approach", Journal of International Marketing, Vol. 12, pp. 86-107.

Papyrina, V. (2007), "When, how, and with what success? The joint effect of entry timing and entry mode on survival of Japanese subsidiaries in China", Journal of International Marketing, Vol. 15, pp. 73-95.

Park, S.H. and Russo, M.V. (1996), "When competition eclipses cooperation. An event history analysis of joint venture failure", Management Science, Vol. 42, pp. 875-890.

Park, S.H. and Ungson, G.R. (1997), "The effect of national culture, organizational complementarity, and economic motivation on joint venture dissolution", Academy of Management Journal, Vol. 40, pp. 279-307.

Parkhe, A. (1993), "Strategic alliance structuring: a game theoretic and transaction cost examination of interfirm cooperation", Academy of Management Journal, Vol. 36, pp. 794-829.

Pauwels, P. and Matthyssens, P. (2004), "Strategic Flexibility in export expansion: growing through withdrawl", International Marketing Review, Vol. 21, pp. 496-510.

Peel, M.J. and Wilson, N. (1989), "The liquidation merger alternative. Some results for the UK corporate sector", Managerial and Decision Economics, Vol. 10, pp. 209-220.

Puck, J.F., Holtbrügge, D. and Mohr, A.T. (2009), "Beyond entry mode choice: explaining the conversion of joint ventures into wholly owned subsidiaries in the People's Republic of China", Journal of International Business Studies, Vol. 40, pp. 388-404.

Puck, J.F., Rogers, H. and Mohr, A.T. (2013), "Flying under the radar: foreign firm visibility and the efficacy of political strategies in emerging economies", International Business Review, Vol. 22, pp. 1021-1033.

Reuer, J.J. (2002), "Incremental corporate reconfiguration through international joint venture buyouts and selloffs", Management International Review, Vol. 42, pp. 237-260.

Reuer, J.J. and Tong, T.W. (2005), "Real options in international joint ventures", Journal of Management, Vol. 31, pp. 403-423.

Reuer, J.J. and Tong, T.W. (2007), "Corporate investments and growth options", Managerial and Decision Economics, Vol. 28, pp. 863-877.

Reuer, J.J. and Zollo, M. (2005), “Termination outcomes of research alliances”, Research Policy, Vol. 34, pp. 101-120. 
Ruhe, C. (2016), "Estimating survival functions after stcox with time-varying coefficients", Stata Journal, Vol. 16, pp. 867-879.

Shi, W. and Iriyama, A. (2010), "Sequence of alliance ownership structure", in Das, T.K. (Eds.), Researching Strategic Alliances. Emerging Perspectives, Information Age Publishing, Charlotte, NC, pp. 133-153.

Shi, W., Sun, S.L., Pinkham, B.C. and Peng, M.W. (2014), "Domestic alliance network to attract foreign partners: evidence from international joint ventures in China", Journal of International Business Studies, Vol. 45, pp. 338-362.

Slater, S. and Robson, M.J. (2012), "Social capital in Japanese-Western alliances: understanding cultural effects", International Marketing Review, Vol. 29, pp. 6-23.

Sørensen, J.B. and Stuart, T.E. (2000), "Aging, obsolescence, and organizational innovation", Administrative Science Quarterly, Vol. 45, pp. 81-112.

Steensma, H.K. and Lyles, M.A. (2000), "Explaining IJV survival in a transitional economy through social exchange and knowledge-based perspectives”, Strategic Management Journal, Vol. 21, pp. 831-851.

Surdu, I., Mellahi, K. and Glaister, K. (2018), "Emerging market multinationals' international equitybased entry mode strategies: review of theoretical foundations and future directions", International Marketing Review, Vol. 35, pp. 342-359.

Tan, Q. and Sousa, C.M.P. (2015), “A framework for understanding firms' foreign exit behavior”, Entrepreneurship in International Marketing (Advances in International Marketing, Vol. 25, Emerald Group Publishing Limited, Bingley, UK, pp. 223-238.

Thornhill, S. and Amit, R. (2003), "Learning about failure: bankruptcy, firm age, and the resourcebased view", Organization Science, Vol. 14, pp. 497-509.

Tong, T.W., Reuer, J.J. and Peng, M.W. (2008), "International joint ventures and the value of growth options", Academy of Management Journal, Vol. 51, pp. 1014-1029.

Tower, A.P., Hewett, K. and Fenik, A.P. (2019), "The role of cultural distance across quantiles of international joint venture longevity", Journal of International Marketing, Vol. 27, pp. 3-21.

Williamson, O.E. (1991), "Comparative economic organization: the analysis of discrete structural alternatives”, Administrative Science Quarterly, Vol. 36, pp. 269-296.

Yang, H., Lin, Z. and Peng, M.W. (2011), "Behind acquisitions of alliance partners: exploratory learning and network embeddedness", Academy of Management Journal, Vol. 54, pp. 1097-1097.

Zeng, S., Xie, X.M., Tam, C.M. and Wan, T.W. (2009), "Relationships between business factors and performance in internationalization: an empirical study in China", Management Decision, Vol. 47, pp. 308-329.

Zhou, K.Z., Gao, G.Y. and Zhao, H. (2017), "State ownership and firm innovation in China: an integrated view of institutional and efficiency logics", Administrative Science Quarterly, Vol. 62, pp. 375-404.

\section{Corresponding author}

Alex Mohr can be contacted at: alexander.mohr@wu.ac.at
Alternative termination modes of IJVs 